\title{
Feasibility Evaluation of Downhole Oil/Water Separator (DOWS) Technology
}

Prepared for:

U.S. Department of Energy Office of Fossil Energy

National Petroleum Technology Office

under Contract W-31-109-Eng-38

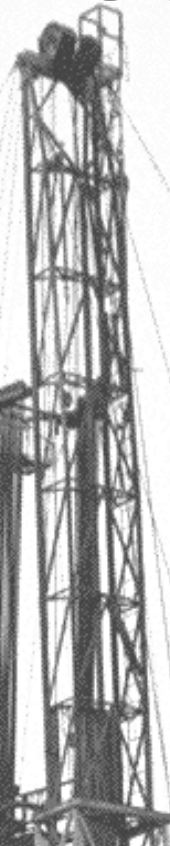

ห

Prepared by:

John A. Veil - Argonne National Laboratory

Bruce G. Langhus - CH2M Hill

Stan Belieu - Nebraska Oil and Gas Conservation Commission 


\section{Table of Contents}

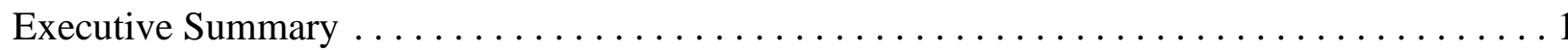

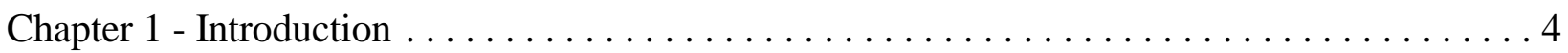

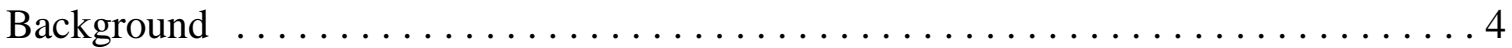

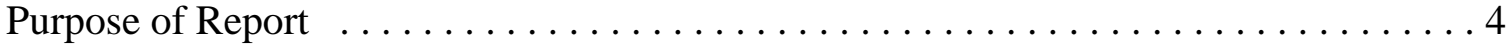

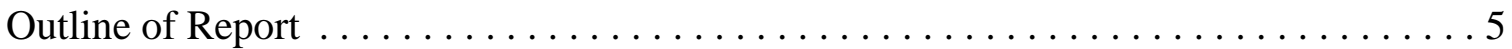

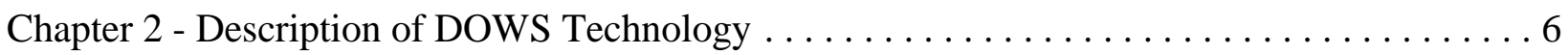

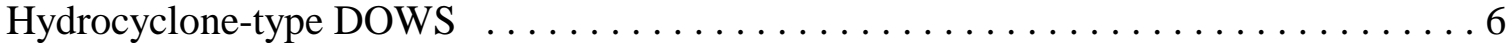

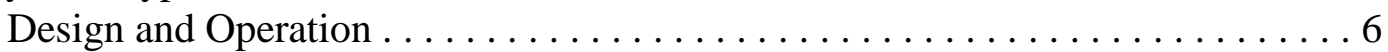

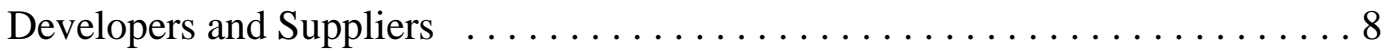

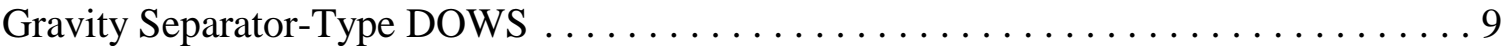

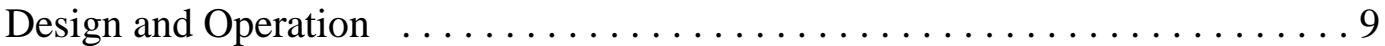

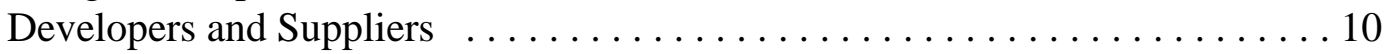

Selecting a Good Candidate Well for a DOWS System $\ldots \ldots \ldots \ldots \ldots \ldots \ldots \ldots 11$

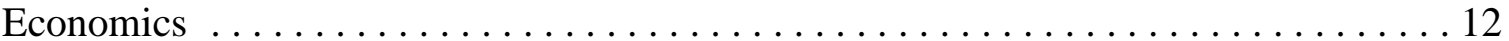

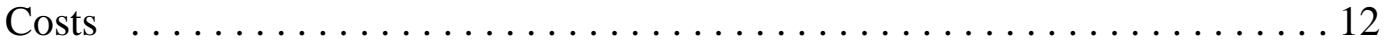

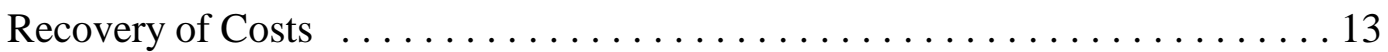

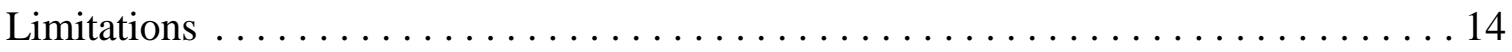

Chapter 3 - Summary and Analysis of Existing DOWS Installations $\ldots \ldots \ldots \ldots \ldots \ldots$

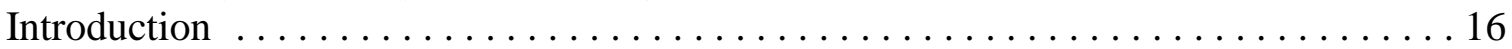

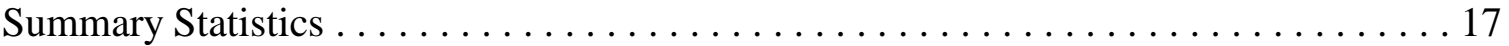

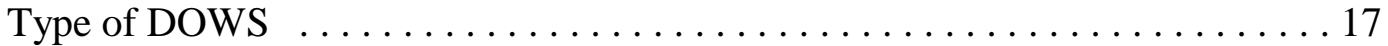

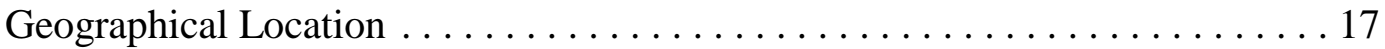

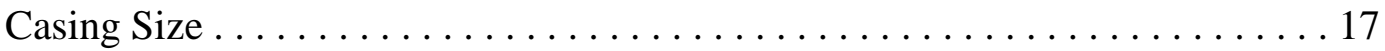

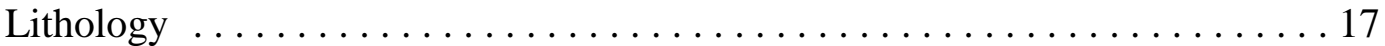

Volume of Oil Produced ............................... 17

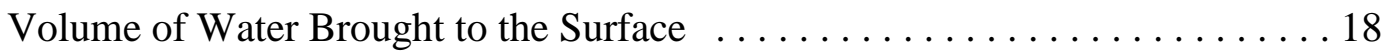

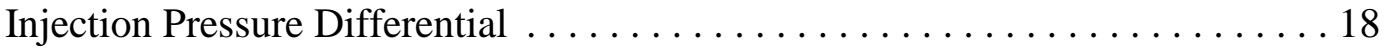

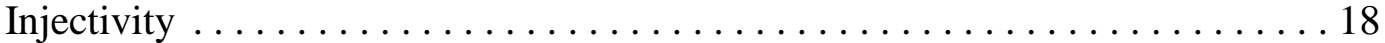

Separation between Production Zone and Injection Zone $\ldots \ldots \ldots \ldots \ldots \ldots 18$

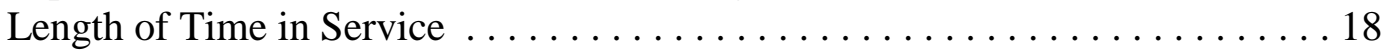

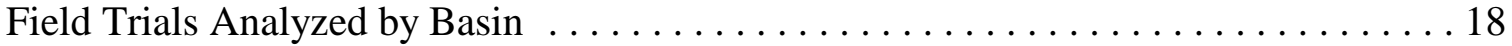

Southeastern Saskatchewan .............................. 19

East-Central Alberta Lower Cretaceous Sands $\ldots \ldots \ldots \ldots \ldots \ldots \ldots \ldots . \ldots . \ldots . \ldots 21$

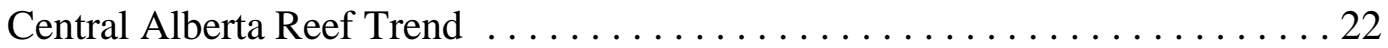

East Texas Field ................................... 24

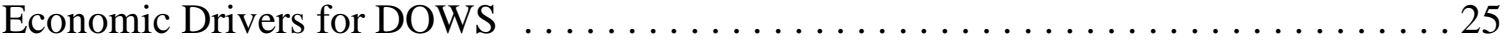

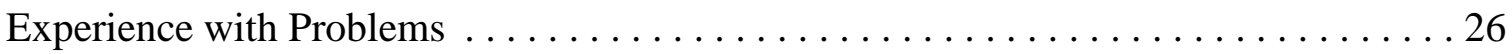




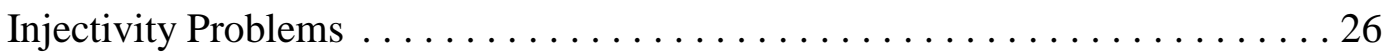

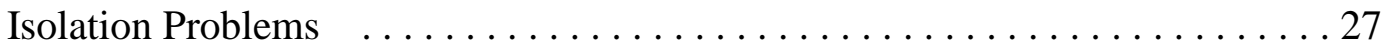

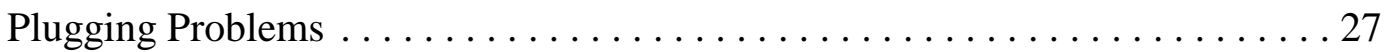

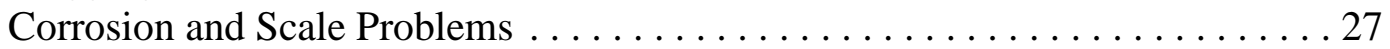

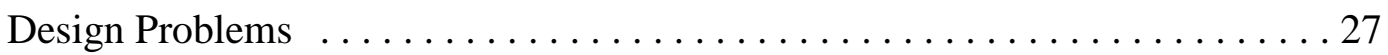

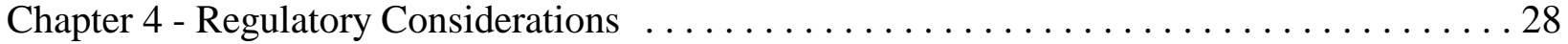

Federal Requirements for Injection of Produced Water $\ldots \ldots \ldots \ldots \ldots \ldots \ldots$

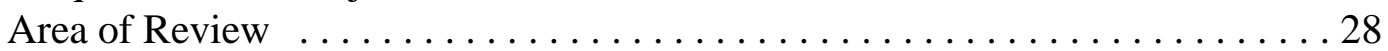

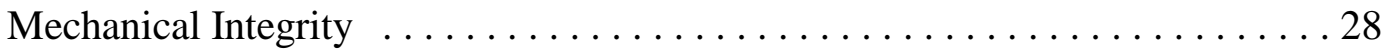

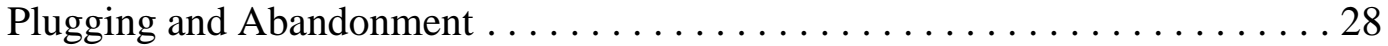

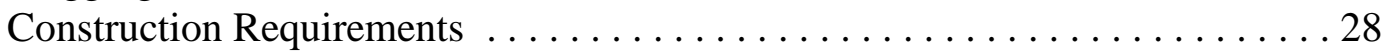

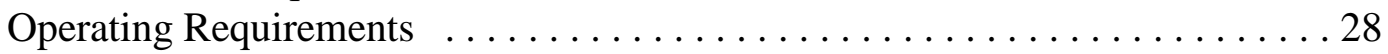

Monitoring and Reporting Requirements . . . . . . . . . . . . . . . . . . 29

State Requirements for Injection of Produced Water . . . . . . . . . . . . . . . . 29

Colorado ................................... 29

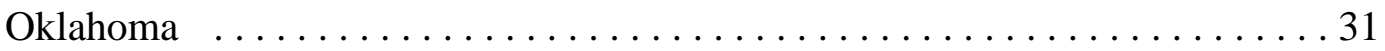

Louisiana ..................................... 32

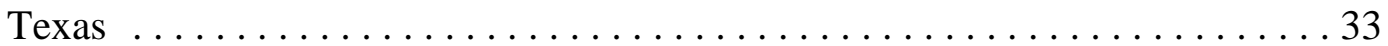

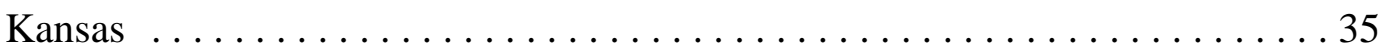

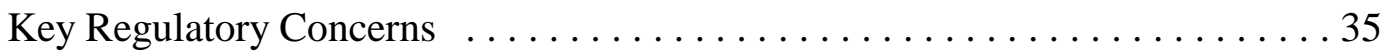

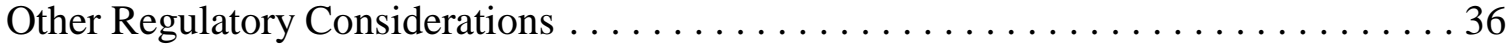

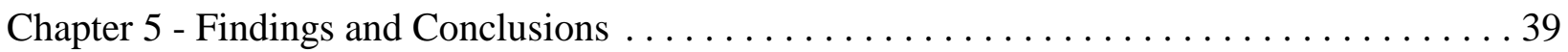

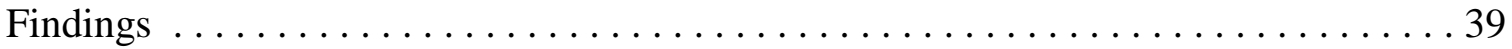

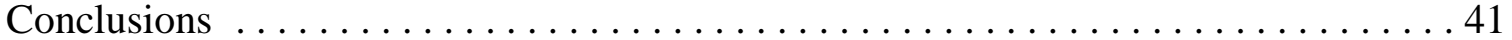

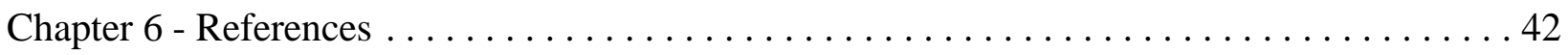

\section{List of Tables}

Table 1 - Capacity Limits for Hydrocyclone-Type DOWS . . . . . . . . . . . . . . . . 7

Table 2 - Production Volumes for DOWS Trials in Southeastern Saskatchewan . . . . . . . . 20

Table 3 - Production Volumes for DOWS Trials in East-Central Alberta Lower Cretaceous

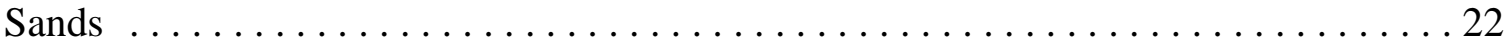

Table 4 - Production Volumes for DOWS Trials in Central Alberta Reef Trends . . . . . . . 23

Table 5 - Production Volumes for DOWS Trials in the East Texas Field . . . . . . . . . . 25

Table 6 - Differences in Regulatory Requirements Between Conventional Injection Wells and

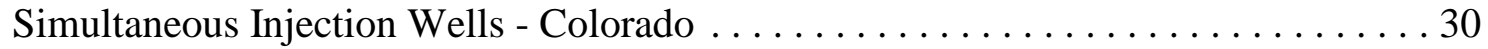


Table 7 - Permitting Requirements for Hydrocyclone-Type DOWS in Texas Compared to

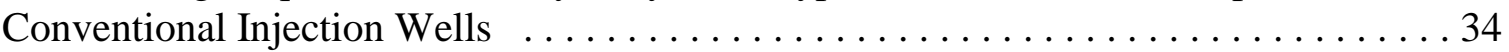

Table A-1: Hydrocyclone-Type DOWS - Performance Data . . . . . . . . . . . . . . . 47

Table A-2: Hydrocyclone-Type DOWS - Well Data . . . . . . . . . . . . . . . . . . . . 49

Table A-3: Hydrocyclone-Type DOWS - Additional Information . . . . . . . . . . . 51

Table A-4: Gravity Separator-Type DOWS - Performance Data . . . . . . . . . . . . . 53

Table A-5: Gravity Separator-Type DOWS - Well Data . . . . . . . . . . . . . . . . . . 54

Table A-6: Gravity Separator-Type DOWS - Additional Information . . . . . . . . . . . . 55

\section{List of Figures}

Figure 1 - Schematic drawing of a hydrocyclone

Figure 2 - ESP Separator System Designs

Figure 3 - Schematic drawing of HydroSep

Figure 4 - Schematic drawing of Q-Sep ${ }^{\mathrm{TM}} \mathrm{H}$

Figure 5 - Schematic drawing of a DAPS showing the lifting and injection cycles

Figure 6 - Schematic drawing of Q-Sep ${ }^{\mathrm{TM}} \mathrm{G}$

Figure 7 - Schematic drawing of Two DOWS Configurations

\section{List of Acronyms}

API
AQWANOT
DAPS
DOE
DHOWS
DOWS
EOR
EPA
HydroSep ${ }^{\mathrm{TM}}$
NPTO
Q-Sep ${ }^{\mathrm{TM}} \mathrm{G}$
Q-Sep ${ }^{\mathrm{TM}} \mathrm{H}$
PT
RMOTC
SDWA
TAPS
UIC
USDW

American Petroleum Institute

type of DOWS sold by REDA Pumps

dual action pump system

U.S. Department of Energy

hydrocyclone-type DOWS developed by C-FER Technologies Inc.

downhole oil water separator

enhanced oil recovery

U.S. Environmental Protection Agency

type of DOWS sold by Centrilift

National Petroleum Technology Office

type of DOWS sold by Quinn Oilfield Supply Ltd.

type of DOWS sold by Quinn Oilfield Supply Ltd.

pressure test

Rocky Mountain Oilfield Testing Center

Safe Drinking Water Act

triple action pump system

Underground Injection Control

underground source of drinking water 


\section{Acknowledgments}

The U.S. Department of Energy's National Petroleum Technology Office (NPTO) provided funding for this project. We particularly acknowledge Nancy Holt of the NPTO for supporting and encouraging this work. We appreciate the assistance of numerous oil and gas operators and equipment suppliers in the United States and Canada in providing information on DOWS installations for us. Finally, we acknowledge the technical advice and assistance provided by Dan Caudle of Argonne National Laboratory and Sound Environmental Solutions. 


\title{
Feasibility Evaluation of Downhole Oil/Water Separator (DOWS) Technology
}

\author{
John A. Veil, Bruce G. Langhus, and Stan Belieu
}

\section{Executive Summary}

The largest volume waste stream associated with oil and gas production is produced water. Treatment and disposal of produced water represent significant costs for operators. A relatively new technology, downhole oil/water separators (DOWS), has been developed to reduce the cost of handling produced water. DOWS may also be referred to as DHOWS or as dual injection and lifting systems (DIALS). DOWS separate oil and gas from produced water at the bottom of the well and reinject some of the produced water into another formation or another horizon within the same formation, while the oil and gas are pumped to the surface. Since much of the produced water is not pumped to the surface, treated, and pumped from the surface back into a deep formation, the cost of handling produced water is greatly reduced. When DOWS are used, additional oil may be recovered as well. In cases where surface processing or disposal capacity is a limiting factor for further production within a field, the use of DOWS to dispose of some of the produced water can allow additional production in that field. Simultaneous injection using DOWS has the added benefit of minimizing the opportunity for contamination of underground sources of drinking water through leaks in tubing and casing during the injection process. Similar devices have been used to a much greater extent for downhole gas/water separation. However, this report is limited to discussion of oil-water separators.

Two basic types of DOWS have been developed - one type using hydrocyclones to separate oil and water and one relying on gravity separation. Hydrocyclone-type DOWS can handle larger flow volumes than gravity separator-type DOWS but are significantly more expensive. Several alternative designs of DOWS are available from different vendors. Hydrocyclones have been paired with electric submersible pumps, rod pumps, and progressing cavity pumps, while gravity separator-type DOWS have utilized only rod pumps. In order to fit into 5.5-inch or 7-inch casings, DOWS are designed as long, slender tools.

Most DOWS installations have been set up with the producing zone above the injection zone. DOWS can potentially be used for waterflooding. DOWS could also be used for reverse coning to reduce the degree of water influx into oil-producing zones.

Conversion of a well from a regular pump to a DOWS is a relatively expensive undertaking. Total costs include the DOWS tool itself and well workover expenses. Costs for the hydrocyclone-type DOWS are fairly high. For example, the cost of an electric submersible pump-based DOWS system is approximately double to triple the cost of replacing a conventional electrical submersible pump and is often in the range of $\$ 90,000$ - $\$ 250,000$, excluding the well workover costs, which can often exceed $\$ 100,000$. Costs are somewhat lower for the gravity 
separation-type DOWS, ranging from $\$ 15,000$ - $\$ 25,000$, and the cost of a complete gravity separator-type DOWS installation was \$140,000 Canadian (Reid 1998).

DOWS installations will not necessarily be cost-effective for all wells. Knowledge of the reservoir and historical production are important before selecting a DOWS installation. The characteristics of wells that are likely to work well with DOWS include, among others, a high water-to-oil ratio, the presence of a suitable injection zone that is isolated from the production zone, compatible water chemistry between the producing and injection zones, and a properly constructed well with good mechanical integrity. DOWS installations in wells that meet these requirements must still remain in good operating conditions for long enough that the accrued monthly savings can offset the initial purchase costs of the equipment. The track record of existing installations is mixed, with some DOWS remaining in service for more than two years but with others failing within a few days. This situation is understandable given that fewer than 40 DOWS have been installed in North America through mid-1998. The technology is new and is still being refined and improved with each successive installation.

This report includes information on 37 DOWS installations in North America. Key statistics from that set of data include:

- More than half of the installations to date have been hydrocyclone-type DOWS (21 compared with16 gravity separator-type DOWS).

- Twenty-seven installations have been in Canada and ten installations have been in the United States.

- Of the 37 DOWS trials described in this report, 27 have been installed in four producing areas southeast Saskatchewan, east-central Alberta, the central Alberta reef trends, and East Texas.

- Seventeen installations were in 5.5-inch casing, 14 were in 7 -inch casing, 1 was in 8.625-inch casing, and 5 were unspecified.

- Twenty of the DOWS installations have been in wells located in carbonate formations and 16 in wells located in sandstone formations. One trial did not specify the lithology. DOWS appeared to work better in carbonate formations, showing an average increase in oil production of $47 \%$ (compared with an average of $17 \%$ for sandstone formations) and an average decrease in water brought to the surface of $88 \%$ (compared with $78 \%$ for sandstone formations).

- The volume of oil increased in 19 of the trials, decreased in 12 of the trials, stayed the same in 2 trials, and was unspecified in 4 trials. The top three performing hydrocyclonetype wells showed oil production increases ranging from $457 \%$ to $1,162 \%$, while one well lost all oil production. The top three gravity separator-type wells showed oil production 
increases ranging from $106 \%$ to $233 \%$, while one well lost all oil production.

- All 29 trials for which both pre-installation and post-installation water production data were provided showed a decrease in water brought to the surface. The decrease ranged from $14 \%$ to $97 \%$, with 22 of 29 trials exceeding $75 \%$ reduction.

- The data on injectivity and the separation distance between producing and injection formations do not correlate well with the decrease in water volume brought to the surface.

Some of the installations experienced problems that impeded the ability of the DOWS to function properly. At least two installations suffered from low injectivity of the receiving zone; in both cases, incompatible fluids contacted sensitive reservoir sands, which plugged part of the permeability. Several installations noted problems of insufficient isolation between the producing and injection zones. If isolation is not sufficient, the injectate can migrate into the producing zone and then short-circuit into the producing perforations. The result will be recycling of the produced water, with oil production rates dropping to nearly zero. Other DOWS have been plugged by fines or sand. Several trials were canceled prematurely because of corrosion and scaling problems. Finally, some of the early installations suffered from poor design features.

Because the technology is still new, no regulatory requirements for DOWS exist in many jurisdictions. The U.S. Environmental Protection Agency (EPA) does not now have a formal position on how to regulate DOWS. Four states (Colorado, Oklahoma, Louisiana, and Texas) have developed either regulations or administrative guidelines for DOWS. Those states regulate DOWS with requirements comparable to or less stringent than those for regular Class II injection wells. There is some concern that EPA might decide that DOWS are not covered under the definition of a Class II well, thereby potentially leading to stricter requirements that could hinder future use of DOWS. It is important for EPA and state regulators to develop reasonable regulatory requirements for DOWS in order not to impede their use in the future. 


\section{Chapter 1 - Introduction}

Background

The largest volume waste stream associated with oil and gas production is produced water. A survey conducted by the American Petroleum Institute estimated that 20.9 billion barrels of produced water were disposed of in 1985 (Wakim 1987). Of this total, 91\% was disposed of through disposal wells or was injected for enhanced oil recovery projects. Treatment and disposal of produced water represents a significant cost for operators.

A relatively new technology, downhole oil/water separators (DOWS), has been developed to reduce the cost of handling produced water. DOWS separate oil and gas from produced water at the bottom of the well and reinject some of the produced water into another formation or another horizon within the same formation, while the oil and gas are pumped to the surface. Since much of the produced water is not pumped to the surface, treated, and pumped from the surface back into a deep formation, the cost of handling produced water is greatly reduced. When DOWS are used, additional oil may be recovered as well. In cases where surface processing or disposal capacity is a limiting factor for further production within a field, the use of DOWS to dispose of some of the produced water can allow additional production within that field. Simultaneous injection using DOWS minimizes the opportunity for contamination of underground sources of drinking water (USDWs) through leaks in tubing and casing during the injection process. This report uses the acronym "DOWS" although the technology may also be referred to as DHOWS or as dual injection and lifting systems (DIALS).

\section{Purpose of Report}

Simultaneous injection using DOWS has the potential to profoundly influence the domestic oil industry. The technology has been shown to work in limited oil field applications in the United States and Canada. Several technical papers describing DOWS have been presented at oil and gas industry conferences, but for the most part, the information on the DOWS technology has not been widely transferred to operators, particularly to small or medium-sized independent U.S. companies.

One of the missions of the U.S. Department of Energy's (DOE's) National Petroleum Technology Office (NPTO) is to assess the feasibility of promising oil and gas technologies that offer improved operating performance, reduced operating costs, or greater environmental protection. To further this mission, the NPTO provided funding to a partnership of three organizations a DOE national laboratory (Argonne National Laboratory), a private-sector consulting firm (CH2M-Hill), and a state government agency (Nebraska Oil and Gas Conservation Commission) to assess the feasibility of DOWS. The purpose of this report is to provide general information to the industry on DOWS by describing the existing uses of 
simultaneous injection, summarizing the regulatory implications of simultaneous injection, and assessing the potential future uses of the technology.

$\underline{\text { Outline of Report }}$

Chapter 2 provides a more detailed description of the two major types of DOWS. Chapter 3 summarizes the existing U.S. and Canadian installations of DOWS equipment, to the extent that operators have been willing to share their data. Data are provided on the location and geology of existing installations, production information before and after installation of the DOWS, and costs. Chapter 4 provides an overview of DOWS-specific regulatory requirements imposed by some state agencies and discusses the regulatory implications of handling produced water downhole, rather than pumping it to the surface and reinjecting it. Findings and conclusions are presented in Chapter 5 and a list of the references cited in the report is provided in Chapter 6. Appendix A presents detailed data on DOWS installations.

This report presents the findings of Phase 1 of the simultaneous injection project, the feasibility assessment. Another activity of the Phase 1 investigation is to design a study plan for Phase 2 of the project, field pilot studies. The Phase 2 study plan is being developed separately and is not included in this report. 


\section{Chapter 2 - Description of DOWS Technology}

Although a full DOWS system includes many components, the two primary components are an oil/water separation system and at least one downhole pump. There are two basic types of separation systems - hydrocyclones and gravity separators - and three types of pumps electric submersible pumps, progressing cavity pumps, and beam pumps. This chapter describes the common types of systems that have been used, the principles upon which they work, criteria for selecting good candidate wells for DOWS, the suppliers of the technology, cost considerations, and limitations of the technology.

The individual components of DOWS technology are well tested and have been proven to work in the oil field. The challenge for DOWS designers is to make separation systems and pumps work together in the confined space of a 7-inch or smaller casing in a bottom-hole environment. DOWS technology holds tremendous promise but is still in its infancy.

Similar devices have been used to a much greater extent for downhole gas/water separation (Grubb and Duvall 1992). However, this report is limited to discussion of oil-water separators.

Throughout this and later chapters, companies or organizations that have developed DOWS technology or are currently suppliers of DOWS technology are mentioned by name. Reference to these companies does not constitute an endorsement of those companies or provide any indication of their performance capabilities. Inclusion of their names in this report is made for historical reference and for the benefit of potential users of the technology. Omission of any other legitimate vendors of DOWS technology is unintentional.

\section{Hydrocyclone-type DOWS}

Design and Operation - Hydrocyclones have been used for surface treatment of produced water for the past 25 years. By the mid-1990s, over 300 hydrocyclones were in use on offshore platforms (Hashmi et al. 1994). Hydrocyclones have no moving parts and separate substances of different density by centrifugal force. Hydrocyclones can separate liquids from solids or liquids from other liquids. The liquid/liquid type of hydrocyclone is used in DOWS. Figure 1 shows a schematic drawing of a hydrocyclone. Produced water is pumped tangentially into the conical portion of a hydrocyclone. Water, the heavier fluid, spins to the outside of the hydrocyclone and moves toward the lower outlet. The lighter fluids, oil and gas, remain in the center of the hydrocyclone where they are carried toward the upper outlet and produced to the surface.

The separation of fluids in a hydrocyclone is not complete some oil is carried along with the water fraction $(<500$ parts per million [ppm] - [Shaw 1998]; $<200 \mathrm{ppm}-$ [Matthews et al. 1996]; <100 ppm - [Bowers et al. 1996]), and a significant portion of water (typically $10 \%$ to 
$15 \%$ [Matthews 1998]) is brought to the surface with the oil and gas fraction. Nevertheless, hydrocyclones can rapidly separate most of the oil from the water fraction. For example, Solanki et al. (1996) report that typically wells with a water-to-oil ratio in the range of 5 to 100 can be treated by a hydrocyclone-type DOWS to produce fluids to the surface with water-to-oil ratios between 1.0 and 2.0 .

Hydrocyclones used in DOWS tend to be narrow and tall. Peachey and Matthews (1994) report that hydrocyclones can be smaller than $50 \mathrm{~mm}$ in diameter and 1-2 meters in length. If a single hydrocyclone does not provide enough capacity to handle the total fluid volume, several hydrocyclones can be installed in parallel. Sobie and Matthews (1997) provide capacity limits in barrels per day (bpd) for hydrocyclone-type DOWS using three different types of pumps and Matthews (1998) offered additional information on the subject. Their data are shown in Table 1.

Table 1 - Capacity Limits for Hydrocyclone-Type DOWS

\begin{tabular}{|l|l|l|l|}
\hline Pump Type & Casing Size (inches) & Total Volume (bpd) & $\begin{array}{l}\text { Maximum Volume to } \\
\text { Surface (bpd) }\end{array}$ \\
\hline \multirow{2}{*}{$\begin{array}{l}\text { Electric } \\
\text { Submersible Pump }\end{array}$} & 5.5 & 3,800 & 440 \\
\cline { 2 - 4 } & 7 & 10,000 & 940 \\
\hline \multirow{2}{*}{$\begin{array}{l}\text { Progressing Cavity } \\
\text { Pump }\end{array}$} & 5.5 & 2,200 & $\sim 450$ \\
\cline { 2 - 4 } & 7 & $\sim 3,800$ & $\sim 1,360$ \\
\hline \multirow{2}{*}{ Rod Pump } & $5.5-85 \%$ water cut & 1,700 & 530 \\
\cline { 2 - 4 } & $5.5-97 \%$ water cut & 1,200 & 70 \\
\cline { 2 - 4 } & $7-85 \%$ water cut & 2,500 & 790 \\
\cline { 2 - 4 } & $7-97 \%$ water cut & 1,900 & 190 \\
\hline
\end{tabular}

Sources: Sobie and Matthews (1997) and Matthews (1998)

Fluids can be either pumped through or pulled through the hydrocyclone. The pumpedthrough mode is more commonly used because flow to the surface can be readily controlled (Shaw 1998), and it provides maximum drawdown potential (Matthews et al. 1996). Some installations have employed dual pump systems (see Figure 2) in which the first pump (the injection pump) is used to pump the fluids into the hydrocyclone and the second, lower-rate pump (the production pump) provides additional power to lift the separated oil and gas to the surface (Matthews et al. 1996). If injectivity is favorable it is possible to achieve substantial power savings with dual pump DOWS (Matthews 1998).

A vast majority of all installations to date are in the standard configuration of injecting to 
a formation below the producing formation. A minor variation on this configuration is disposal to a lower portion of the producing zone. Care must be taken in this configuration that the injected water does not short-circuit back to the producing zone, thereby increasing the water-tooil ratio.

One Canadian installation at a Talisman Energy Inc. well disposed of water to a formation above the producing zone (Reid 1998).

Several other configurations may be useful in some applications. Schrenkel (1997) and Chrusch (1996) discuss crossflooding, in which two wells outfitted with DOWS provide waterflood flows to each other, and horizontal and multi-lateral well completions. Those two authors and Kjos et al. (1995) describe the use of DOWS for suppression of the coning that can cause water influx into oil-producing zones. Sobie and Matthews (1997) describe three dual-leg horizontal wells in southeast Saskatchewan that were fitted with DOWS.

Peachey et al. (1997) provide additional information about 18 hydrocyclone-type DOWS that had been installed through mid-1997. In terms of formation type, 6 had been installed in carbonate formations and 12 in sandstone formations. Thirteen of the installations were made in vertical wells and 5 in deviated wells. Eleven of the installations were made in wells having 5.5-inch casings and 7 were made in wells having 7-inch casings. In terms of system design, 13 used electric submersible pumps, 4 used progressing cavity pumps, and 1 used a beam pump. Three installations employed a single pump, while 15 used dual pumps. Six trials involved a single hydrocyclone liner, 11 used two hydrocyclone liners, and 1 trial used three hydrocyclone liners.

Developers and Suppliers - The leading developer of hydrocyclone-type DOWS is C-FER Technologies Inc. of Edmonton, Alberta. Preliminary C-FER studies in the early 1990s indicated that downhole separation of oil and water was feasible through combining conventional oil well pumps with hydrocyclones. C-FER organized a joint industry project involving numerous industry partners to develop and field test prototype separation systems using electric submersible pumps, progressing cavity pumps, and beam pumps (Matthews et al. 1996; Solanki et al. 1996). The hydrocyclone-type DOWS system developed and patented by C-FER has been licensed to both REDA Pumps, a Camco International Company, and Centrilift, a Baker Hughes company, for the electric submersible pump version. C-FER has licenses pending with BMW Pump Inc. for the progressing cavity pump version and with Quinn Oilfield Supply Ltd. for the rod pump version of the technology. The majority of the C-FER trials to date have utilized electric submersible pumps supplied by REDA Pumps and hydrocyclones supplied by Vortoil Separation Systems, now part of Baker Hughes Processing. Some of those trials are described in the literature (Matthews et al. 1996; Bowers et al 1996; Solanki et al. 1996; Schrenkel 1997; Peats and Schrenkel 1997). REDA markets its DOWS under the trade name AQWANOT ${ }^{\mathrm{TM}}$ and Centrilift has named its system the HydroSep ${ }^{\mathrm{TM}}$. HydroSep ${ }^{\mathrm{TM}}$ systems had been installed in at least four wells through April 1998, but no published literature is available on the actual trials. A schematic drawing of the HydroSep System is shown in Figure 3. 
Quinn Oilfield Supply Ltd. markets a rod pump DOWS system, the Q-Sep ${ }^{\mathrm{TM}} \mathrm{H}$, that was developed in conjunction with C-FER Technologies Inc. It operates with two pump chambers on the same sucker rod string. Fluids are pulled through the hydrocyclone, with the oil moving to the upper pump chamber and the water to the lower pump chamber. On the pump upstroke, an oil/water mixture is pumped to the surface and water is pumped to an injection zone. A Q-Sep ${ }^{\mathrm{TM}}$ $\mathrm{H}$ was installed in two wells. One of these installations was later removed after experiencing corrosion, sand, and mechanical problems (Collins 1998). A schematic drawing of the Q-Sep ${ }^{\mathrm{TM}}$ $\mathrm{H}$ is shown in Figure 4.

BMW Pump Inc. (now part of Weatherford) worked with C-FER to develop a progressing cavity pump DOWS system that uses hydrocyclones. No data on the design of this device was available from either BMW Pump or C-FER, although Peachey et al. (1997) indicates that as of mid-1997, four trials of progressing cavity pump DOWS had been made. We have been able to gain some information on one trial of a BMW Pump-DOWS that ran from October 1997 to March 1998 when the DOWS was removed due to a failure of the transfer tube. The DOWS reduced the volume of water brought to the surface by about $75 \%$ but did not change the volume of oil brought to the surface. The operator indicated that the trial was successful but did not share any economic information (Browning 1998). Sobie and Matthews (1997) report on a second well using a progressing cavity pump DOWS. The well had previously been shut in for three years because of the limitations of the surface water handling capacity. Both single and dual pump systems were tested on this well; these DOWS provided about 18 months of continuous operation with significant reduction in the volume of water brought to the surface.

\section{Gravity Separator-Type DOWS}

Design and Operation - Oil and water exist as separate fractions downhole. Emulsions are typically formed when oil and water are mixed by pumping. The gravity separator type of DOWS takes advantage of the gravity separation of oil and water that occurs in the casing/tubing annulus. The dual action pumping system (DAPS), which is the most commonly used type of gravity separator DOWS, is constructed by modifying a rod pump to contain two separate pump chambers and inlets, and adding an injection valve and packer. The upper inlet is located at an elevation near the oil/water interface, so that a mixture of oil and water enters the upper pump and is brought to the surface on the upstroke. The lower inlet is located below the oil/water interface, so that primarily water enters the lower pump and is subsequently injected during the downstroke. Stuebinger et al. (1997) report that some samples of the injectate were measured and found to contain less than $100 \mathrm{ppm}$ of free oil. Proper sizing of the two pump chambers is critical in preventing oil from being disposed of to the injection zone. If the working fluid level drops below the upper inlet, no fluids will be pumped to the surface, and both water and oil will be injected to the injection formation.

Figure 5, reproduced from Stuebinger et al. (1997), is a schematic drawing of the DAPS. The figure also indicates the fluid flow in the upper and lower chambers during both the upward and downward strokes of the pump. The sucker rod strings of conventional rod pumps are 
designed to tolerate a tension strain but not a compression strain. The force required to inject water into a formation can place an undue compression strain on sucker rods, so sinker bar weights are often added above the top pump on a DAPS to overcome the injection pressure (Stuebinger et al. 1997).

DAPS have been installed in over a dozen wells. DAPS are most commonly used on wells with 5.5-inch casings. Because of size constraints, the largest DAPS that will work in that size casing can pump about 1,000 bpd (Stuebinger et al. 1997). As of early 1998, DAPS have not been miniaturized sufficiently to work cost-effectively in wells with casing sizes of less than 5.5 inches.

Another type of gravity separator DOWS, the Q-Sep ${ }^{\mathrm{TM}} \mathrm{G}$, functions somewhat differently from the DAPS in that both the upper and lower pumps operate on the upstroke. By disposing of water on the upstroke, compression of the sucker rod string does not occur, and sinker bar weights are not needed. During the downstroke, the oil and water in the casing/tubing annulus are allowed an additional quiescent period for enhanced gravity separation. A schematic drawing of the Q-Sep ${ }^{\mathrm{TM}} \mathrm{G}$ is shown in Figure 6. The Q-Sep ${ }^{\mathrm{TM}} \mathrm{G}$ has been installed in only one well to date.

Stuebinger et al. (1997) suggest that DAPS can be useful in waterflooding certain reservoirs at little additional cost. Wells equipped with DAPS could both produce oil and provide water for flooding a second reservoir.

In June 1998, Texaco announced a patent for a modified version of the DAPS, the triple action pumping system (TAPS), that can be used when the injection formation is tight (McKinzie et al. 1998). The TAPS includes an upper piston that operates on the upstroke and two pistons (the middle and lower) that operate on the downstroke. Like the DAPS, the piston operating on the upstroke moves oil and water to the surface. The middle piston has a larger surface area than the lower piston. The pressure applied by the rod string to the middle piston is multiplied by the ratio of the surface areas of the middle and lower pistons. Although injection pressures can be increased through the use of the third piston, injection volumes are concomitantly reduced by the ratio of the surface areas of the lower and middle pistons.

Developers and Suppliers - Texaco developed the concept of the DAPS and approached Axelson Inc. to assist in constructing the actual tool. Texaco holds the patent on the DAPS and granted Axelson manufacturing and sales rights. Axelson was later acquired by Dresser Oil Tools, the current vendor for DAPS. The Q-Sep ${ }^{\mathrm{TM}} \mathrm{G}$ was developed by Quinn Oilfield Supply Ltd. in partnership with Petro-Canada.

Selecting a Good Candidate Well for a DOWS System 
The prospect of reducing produced water handling and disposal costs and possibly producing more oil through installation of a DOWS is attractive. However, not all wells are good candidates for cost-effective DOWS installation. Some formations and reservoirs are not conducive to downhole separation and injection. Operators will not undertake the large initial cost of a DOWS unless the system is likely to pay back its costs. Several authors have indicated the criteria they have used in selecting candidate wells for installations of hydrocyclone-type DOWS systems. Matthews et al. (1996) and Chachula et al. (1996) describe the selection criteria used to site three hydrocyclone-type DOWS systems in the Alliance field in east-central Alberta, Canada. The operator was already experiencing produced water handling limitations and could decrease costs by reducing the volume of produced water brought to the surface. From a production standpoint, wells had to have a water-to-oil ratio of 8 or higher and productivity of greater than 1,260 bpd. The reservoir had to contain sufficient incremental reserves and provide a suitable disposal zone. The casing had to be at least 5.5 inches in diameter, and the well bore had to have good mechanical integrity and a minimum separation of about 80 feet between the production zone and disposal zone. The well bore had to be already open below the production zone so that additional drilling would not be necessary.

Peats and Schrenkel (1997) describe the selection criteria used to site a hydrocyclonetype DOWS in the Swan Hills Unit One field in Alberta, Canada. Only wells having a water cut of $94 \%$ (a water-to-oil ratio of about 16) were considered. Because a DOWS sized to fit in a 5.5inch casing would be very long and costly, a well with 7-inch casing was preferable to maximize the rate of production and allow for better clearance. Wells with a history of asphaltine and scale problems or wells with high gas-to-oil ratios were avoided. After several rounds of screening, a leading candidate well was selected. Three-dimensional geological models were used to assess the characteristics of the candidate well and other nearby producing wells. Before installing the DOWS, production and economic forecasting were performed.

Stuebinger et al. (1997) identify several screening criteria for siting DAPS. The most important is the availability of a suitable injection zone that is isolated from and at least 10 feet deeper than the production zone. The pressure required to inject water cannot be excessive. In the cases examined by Stuebinger et al., the injection pressure gradient must be less than 0.45 pounds per square inch ( $\mathrm{psi}$ ) per foot of depth. The chemistry of the produced water must be compatible with the injection zone; it is usually inadvisable to mix water from carbonate and sandstone formations. As with all other types of DOWS, the casing must be in sufficiently good condition to withstand setting of a packer and the pressures needed for injection. In order to promote proper gravity separation of oil and water, the wellbore should be as vertical as possible between the upper and lower intakes. Wells producing cold, heavy crude oil with API gravity of $10^{\circ}$ or less may not be good candidates for gravity separation. Matthews (1998) notes that $15^{\circ}$ API gravity may be a more appropriate cut off for gravity separation-type DOWS. Peachey et al. (1997) reinforce this latter point in stating that gravity separation systems are most likely to be feasible in situations with warm, low-volume, large-diameter casings where a light gravity oil is being produced in relatively large droplets. 
Knowledge of the reservoir and historical production are important before selecting a DOWS installation. Sobie and Matthews (1997) noted three factors that are critical for a successful installation -- accurate reservoir pressure, injection zone pressure, and inflow performance data.

\section{$\underline{\text { Economics }}$}

Costs - Because DOWS development is still an emerging technology, with each installation needing a case-by-case engineering analysis, costs are not easy to characterize. Many of the early trials were done in more of a research mode than a cost-minimizing mode. Further, many operators are reluctant to provide their detailed costs. When we were able to obtain cost estimates, they typically were rough estimates, and it was difficult to determine which component costs were included and which were omitted from the provided estimates. Some general comments regarding cost can be made, however:

- $\quad$ All DOWS installations to date have been retrofits of existing wells.

- $\quad$ The DOWS replaced existing well pumps.

- $\quad$ DOWS are more expensive than standard pumps. Wells typically had to undergo a workover before the DOWS could be installed and production resumed.

- $\quad$ Some installations included optional monitoring equipment.

Costs for the hydrocyclone-type DOWS are relatively high. When a HydroSep ${ }^{\mathrm{TM}}$ system replaces an existing electric submersible pump, and the horsepower and instrumentation requirements are the same, the costs are approximately double to triple the cost of just the pump (Fox 1998). Cost estimates provided by REDA for installation of an AQWANOT ${ }^{\mathrm{TM}}$ system are typically in the range of $\$ 150,000$ - $\$ 250,000$. Matthews (1998) reports costs as low as $\$ 90,000$. This cost includes the electric submersible pump, hydrocyclone, cable, transformer, and monitoring, but does not include the cost of a workover (Naylor 1998a). The cost, in Canadian dollars $^{1}$, for one particular Q-Sep ${ }^{\mathrm{TM}} \mathrm{H}$ system using a rod pump is estimated at $\$ 140,000$ (Reid 1998).

Sobie and Matthews (1997) provide economic information for two electric submersible pump-operated and one rod pump-operated hydrocyclone-type DOWS installations. For the two electric submersible pump-type installations, the well conversion costs were $\$ 125,000$ and $\$ 100,000$ respectively, the cost of the DOWS units were $\$ 150,000$ and $\$ 210,000$, respectively,

${ }^{1}$ For reference purposes, as of December 22, 1998, the rate of exchange between Canada and the United States is approximately 1 U.S. dollar $=1.55$ Canadian dollars or 1 Canadian dollar $=0.64$ U.S. dollars. 
and the estimated payback periods were 36 months and 12 months, respectively. For the rod pump-type installation, the well conversion cost was $\$ 100,000$, the DOWS cost was $\$ 70,000$, and the estimated payback period was 12 months. Although not stated in the reference, it is assumed that the costs were expressed in Canadian dollars. The cost savings resulted from avoidance of emulsion treating costs, trucking costs, and additional piping costs, and delays in expending capital for well conversion.

Costs are somewhat lower for the gravity separation-type DOWS. Costs for the DAPS pumps at four Canadian installations, in Canadian dollars, range from \$15,000 - \$25,000 (information taken from data sheets provided by Grenier [1998], Krug [1998], and Scharrer [1998]; and from Elphingstone [1998a]). The costs for a complete DAPS installations at a Talisman Energy facility in Saskatchewan are reported as \$140,000 Canadian (Reid 1998).

McKinzie et al. (1998) report that DAPS typically require about $30 \%$ less energy to run than standard rod pumps because significantly less water is lifted to the surface. DAPS may also extend the service life for rods and tubing where wear is a problem because the pump jack can run at a lower speed since pumping occurs on both the upstroke and the downstroke.

Recovery of Costs - DOWS can result in cost savings in a variety of ways. Operating costs are typically reduced. Less energy is used to lift the produced water to the surface and to return it to an injection formation. The use of treatment chemicals is greatly reduced. Environmental costs, including site remediation, are generally lower. Handling and piping less produced water at the surface minimizes the likelihood of spills or leaks of salty water onto soils. Pumping less water to the surface and back down hole, past drinking water aquifers, presents fewer opportunities for contamination of drinking water. Some DOWS installations have resulted in increased oil production.

In many locations, the capacity of existing water-handling facilities can be a limiting factor for production. By shifting disposal of some of the produced water to a DOWS, additional total fluids, including oil, can be produced. Installing DOWS may be less expensive than expanding surface water-handling capacity. For example, in some remote Canadian areas, produced water is trucked to central treatment and disposal locations. Stuebinger et al. (1997) indicate that trucking costs there range from $\$ 0.35$ to $\$ 1.50 / \mathrm{bbl}$. With trucking costs this high, the cost of a DAPS system can be paid off in as little as two months. Even when trucking costs are not high, third-party processing fees and water disposal fees can be high. Stuebinger et al. (1997) note that such costs in Canada can range from $\$ 0.30$ to $\$ 0.70 / \mathrm{bbl}$, resulting in pay back periods of about four months.

Peats and Schrenkel (1997) do not indicate the total cost for installation of the AQWANOT ${ }^{\mathrm{TM}}$ system in the Swan Hills Unit One field, but report that Anderson Exploration, the well's operator, had predicted that the costs of DOWS installation could be recovered in 3.2 months. The original project budget was overspent by $\$ 100,000$, but the project still 
recovered its costs within 4.3 months. This field of 136 wells was limited by the capacity of its surface water-handling facilities. By shifting disposal of much of the produced water from the candidate well to downhole injection, an additional 3,450 bpd of surface water-handling capacity became available for the field. This allowed a second well to increase its oil production by $80 \mathrm{bpd}$. The rapid payback period was also accomplished through an increase in oil production of $82 \mathrm{bpd}$ in the candidate well because of additional drawdown of the reservoir.

PanCanadian Petroleum faced a similar problem with insufficient surface water-handling capacity in the Alliance field. Matthews et al. (1996) report that PanCanadian evaluated two options expanding surface water-handling facilities or installing DOWS. The DOWS option was estimated to be less costly in terms of both capital and operating costs, so PanCanadian installed DOWS in three wells. The DOWS were effective in increasing oil production from those wells and freeing up surface water-handling capacity so other wells in the field could increase production. Matthews et al. (1996) do not provide actual costs or payback periods.

Chevron installed a DAPS in a well in East Texas in September 1995. The total cost of the project, including an acid job on the injection formation, was recovered within 64 days (Stuebinger et al. 1997). As of April 1998, the unit was having some problems and was due for a workover. However, the unit had performed well until January 1998 (Roberts 1998).

\section{$\underline{\text { Limitations }}$}

Most published articles about DOWS tell about the success stories. It is true that good installations can be successful and recover costs rapidly. However, although some of the trials have been successful (see Chapter 3 for details), others have failed or have worked for only a short period of time. Some of the limitations and site-specific problems that have been identified are listed below:

- $\quad$ A candidate well with less than ideal characteristics was chosen.

- $\quad$ The disposal zone was too close to the production zone and short-circuiting of water occurred.

- Mechanical problems, such as downhole shorting and physical damage to equipment, occurred. Some of these problems have been eliminated in later equipment designs.

- $\quad$ The presence of sand eroded pump components and fines clogged valves.

- $\quad$ Downhole chemistry caused corrosion and scaling problems.

- $\quad$ A gravity separation-type system was installed in a well that did not allow adequate time or space for separation of oil and water. 
Each trial has been a learning experience for DOWS developers and vendors. Further refinements of the technology should improve the success rate. 


\section{Chapter 3 - Summary and Analysis of Existing DOWS Installations}

$\underline{\text { Introduction }}$

This chapter summarizes the information gathered on 37 historical field trials of the various DOWS installations. It is likely that more than this number of DOWS have been installed as of the summer of 1998; however, we were unable to obtain information from operators or equipment vendors on the other trials. This report can only present a snapshot in time of the number of installed DOWS; each month, additional DOWS are being installed. We believe that the information presented in this chapter on the 37 trials is representative of the trials to date.

Many operators have been very cooperative with the authors. We are grateful for that cooperation, for without it, data would be severely limited. Much of the work performed by C-FER has been done as a proprietary joint industry project. Data and results of that project are only shared with organizations that pay a share of the joint industry project costs. Consequently, with the exception of a few pieces of data that C-FER has published in conference papers, most of the C-FER data were not available to the authors for inclusion in this report. Several operators elected not to share data with us because they felt that information on their DOWS, collected at their own expense, gave them a competitive advantage. Some of the data reported in this chapter are very specific and detailed. For example, Chevron spent over three weeks performing injectivity tests on their HAS \#1107 well in the Wickett Field in West Texas (Levan 1997). These data, being site-specific and long-term, are considered very reliable. Other operators reported only field-wide averages for injectivity or pressure.

Data on the 37 trials are summarized in Appendix A. To the extent possible, data are provided on:

- operator name;

- well name;

- producing field;

- state or province;

- producing formation name;

- producing formation lithology;

- type of DOWS;

- diameter of production casing;

- injection zone;

- injectivity;

- injection pressure differential;

- separation between production zone and injection zone;

- oil produced to surface before and after DOWS installation;

- water produced to surface before and after DOWS installation;

- starting date of trial; 
- ending date of trial;

- comments; and

- source of information.

\section{$\underline{\text { Summary Statistics }}$}

Appendix A represents the most extensive publicly available database on DOWS. Some of the general trends in the data are discussed in this section.

Type of DOWS - More than half of the installations to date have been hydrocyclone-type DOWS (21 compared to16 gravity separator-type DOWS).

Geographical Location - Twenty-seven installations have been in Canada (18 in Alberta, 8 in Saskatchewan, and 1 unspecified). Ten installations have been in the United States (5 in Texas, 2 in Wyoming, and 1 each in Colorado, New Mexico, and Illinois). The U.S. installations are more heavily weighted towards gravity separator-type DOWS. About $37 \%$ of all gravity separator-type DOWS are U.S. installations, while only about $20 \%$ of all hydrocyclone-type DOWS are U.S. installations.

Casing Size - Among hydrocyclone-type DOWs, 8 installations were in 5.5-inch casing, 11 were in 7-inch casing, 1 was in 8.625-inch casing, and 1 was unspecified. Among gravity separatortype DOWS, 9 were in 5.5-inch casing, 3 were in 7-inch casing, and 3 were unspecified.

Lithology - Overall, 20 of the DOWS installations have been in wells in carbonate formations and 16 in wells in sandstone formations. One trial did not specify the lithology. The number of installations of gravity separator-type DOWS is equally split between carbonate and sandstone formations, while more hydrocyclone-type DOWS have been installed in carbonate formations (12 compared to 8 for sandstone formations). DOWS appeared to work better in carbonate formations, showing an average increase in oil production of $47 \%$ (compared to $17 \%$ for sandstone formations) and an average decrease in water brought to the surface of $88 \%$ (compared to $78 \%$ for sandstone formations).

Volume of Oil Produced - The volume of oil production increased in 19 of the trials, decreased in 12 of the trials, stayed the same in 2 trials, and was unspecified in 4 trials. For hydrocyclonetype DOWS, 11 trials showed an increase in oil production, 7 trials showed a decrease, and 3 trials were either unchanged or did not specify oil production. For gravity separator-type DOWS, 8 trials showed an increase in oil production, 5 trials showed a decrease, and 3 trials were either unchanged or did not specify oil production. The top three performing hydrocyclonetype wells showed oil production increases ranging from $457 \%$ to $1,162 \%$, while one well lost all oil

production. The top three gravity separator-type wells showed oil production increases ranging from $106 \%$ to $233 \%$, while one well lost all oil production. 
Volume of Water Brought to the Surface - All 29 trials for which both pre-installation and postinstallation water production data were provided showed a decrease in water brought to the surface. For hydrocyclone-type DOWS, the decrease ranged from 29\% to 97\%, with 13 of 16 trials exceeding $75 \%$ reduction in water brought to the surface. For gravity separator-type DOWS, the decrease ranged from $14 \%$ to $97 \%$, with 9 of 13 trials exceeding $75 \%$ reduction in water brought to the surface.

Injection Pressure Differential - This parameter indicates the difference in formation pressure between the injection zone and the production zone. Pressure differential data were reported for only 15 of the 37 trials, with 9 of those indicating no differential, 5 indicating a positive pressure differential (the injection zone has higher pressure than the production zone) ranging from $40 \mathrm{psi}$ to $300 \mathrm{psi}$, and 1 indicating a negative pressure differential (the injection zone has lower pressure than the production zone) of 412 psi. The results do not show a strong correlation between pressure differential and the volume of water brought to the surface. No data were available on the total water injected in each of these trials. It is likely that a high pressure differential would restrict the amount of water that could be injected, and this would perhaps increase the amount of produced water reaching the surface and decrease the effectiveness of the installation.

Injectivity - Injectivity data were reported for only 10 of the 37 trials. The results do not show a strong trend. For hydrocyclone-type DOWS, 7 installations had injectivity values ranging from 20 to $43 \mathrm{bpd} / \mathrm{psi}$. The reduction in water brought to the surface in these wells following DOWS installation ranged from $75 \%$ to $95 \%$. An eighth trial had an injectivity of only $2 \mathrm{bpd} / \mathrm{psi}$, but it showed a reduction in water to the surface of $81 \%$. Injectivity data are available for only two of the gravity separator-type DOWS. The two trials had an injectivities of 6 and $13 \mathrm{bpd} / \mathrm{psi}$ and reductions of water brought to the surface of $45 \%$ and $14 \%$, respectively.

Separation between Production Zone and Injection Zone - Data on vertical separation between production zones and injection zones were presented for 20 trials. For hydrocyclone-type DOWS, the separations ranged from 12 to 2,300 feet, and for gravity separator-type DOWS, the separations ranged from 24 to 1,137 feet. There is no apparent relationship between the separation distance and the decrease in water volume brought to the surface.

Length of Time in Service - Appendix A contains only 11 trials with both start and end dates for DOWS operations. Those trials ranged in duration from 1 to 10 months. Many of the other trials provide start dates but not end dates; these may still be in operation.

\section{$\underline{\text { Field Trials Analyzed by Basin }}$}

Of the 37 trials, 27 have been installed in just four production areas southeastern Saskatchewan, east-central Alberta, the central Alberta reef trend, and the East Texas field. These four regions have a sufficient number of DOWS trials so that some generalizations can be made regarding the performance of the DOWS methodology. Other areas (e.g., the Illinois Basin) have only a single DOWS trial. Results of a single trial cannot be extrapolated to general statements 
about the performance of the DOWS methodology in that setting. Problems or successes with a single trial, such as the corrosion problems encountered by Texaco in the Illinois Basin trial, may be a regional phenomenon or may be peculiar to that well. More trials will be needed in the Illinois Basin before generalizations can be made. Within the four producing areas, the numbers of DOWS trials are significant and the production statistics are distinctive for each area. However, Matthews (1998) notes that C-FER has seen both good and bad experience within the same pool.

Taken as a set, each area can be interpreted as having either good potential for success or being unsuitable for DOWS applications. Although not every variable has been researched in each basin, the producing characteristics of the basins are sufficiently known that future research can be aimed at the basins of interest. For example, the central Alberta reef trend performed well with the DOWS tools. Consequently, further research could be performed on similar formations, such as the Michigan Silurian reefs, to see if they also perform well with DOWS. Each of the four settings where sufficient trials have been installed is discussed below in terms of the geologic and reservoir setting, production performance, problems, and identification of other comparable fields in which to try DOWS tools, particularly U.S. fields.

\section{Southeastern Saskatchewan}

Seven wells in southeastern Saskatchewan have had DOWS installations. Three trials involved gravity separation-type DOWS and four involved hydrocyclone-type DOWS.

Geologic and Reservoir Setting: Seven wells produce oil from Lower Mississippian Mission Canyon equivalents trapping oil in an up-dip erosional edge of the Canadian portion of the Williston Basin. The oil-productive carbonates are mostly bioclastic and oolitic limestones laid down as carbonate facies that overlay the Lodgepole Formation (Souris Valley). The Mission Canyon equivalents are shelf-margin limestones. These limestones are separated by thin chalk and anhydrite zones (Richards et al. 1994). The bulk of the oil produced in Saskatchewan is out of Lower Mississippian carbonates in this setting. The discovery pressure of the Mission Canyon Formation is approximately $2,600 \mathrm{psi}$. The reservoir temperature ranges from $145^{\circ} \mathrm{F}$ to $155^{\circ} \mathrm{F}$. The porosity of the oil-producing section ranges from 10 to $17 \%$, and the matrix permeability is between 10 and 20 millidarcies. The oil ranges from $29^{\circ}$ to $35^{\circ}$ API gravity. Produced water is often injected into zones such as the fractured carbonates of the Souris Valley Formation, which takes water on a vacuum. Oil fields in this setting have very strong water drives that cause high water cuts. Water handling costs are high in this part of the Williston Basin because of the shortage of disposal wells and the resulting high transportation costs.

Production Performance: The performance of these DOWS installations has been variable. Table 2 shows the production of oil and water from these wells before and after DOWS installation. Average oil production increased by nearly $30 \%$ while average water produced to the surface decreased by nearly $90 \%$. The Talisman Creelman well doubled oil production while cutting produced water to only $5 \%$ of its original volume. However, in four of the trials, the 
volume of oil produced actually declined, and in a fifth case the volume remained the same. In this region, the impetus for installing DOWS is primarily reducing produced water pumped to the surface rather than increasing oil production (Sobie and Mathews 1997), and in that regard, the installations were a big success. Six of the seven wells showed reductions in produced water pumped to the surface following DOWS installation. Four of these wells showed greater than $75 \%$ reduction in produced water volume pumped to the surface. No post-installation produced water data were available for the Southward trial, so its performance cannot be evaluated.

Table 2 - Production Volumes for DOWS Trials in Southeastern Saskatchewan

\begin{tabular}{|c|c|c|c|c|c|}
\hline \multirow{3}{*}{ Operator and Well } & \multirow[b]{3}{*}{ Type of DOWS } & \multicolumn{4}{|c|}{ Production (bbl/day to surface) } \\
\hline & & \multicolumn{2}{|c|}{ Pre-DOWS } & \multicolumn{2}{|c|}{ Post-DOWS } \\
\hline & & Oil & Water & Oil & Water \\
\hline Talisman Creelman 3c7-12 & hydrocyclone & 113 & 2,516 & 277 & 126 \\
\hline Talisman Handsworth 4d8-16 & hydrocyclone & 88 & 1,700 & 50 & 189 \\
\hline Tri-Link Bender 9-30 & hydrocyclone & 35 & 976 & 35 & 227 \\
\hline Talisman Handsworth 2d5-13 & hydrocyclone & 63 & 1,260 & 38 & 63 \\
\hline Talisman Tidewater 4-27 & gravity separator & 16 & 252 & 33 & 139 \\
\hline Richland Parkman 1-17 & gravity separator & 20 & 220 & 15 & 190 \\
\hline Southward 11-13 & gravity separator & 24.5 & 458 & 16 & no data \\
\hline Average & & 51 & 1,229 & 66 & 156 \\
\hline
\end{tabular}

Problems: Several southeastern Saskatchewan wells have had problems with corrosion, although the degree of corrosion has not been greater than average for DOWS installations. None of these wells has a wide separation between the producing and disposal zone. Insufficient separation can cause some degree of recycling of fluid outside the casing, either within channels through the cement in the borehole or through fractures in the formation. Recycling may cause a drop in oil production. Indeed, four of the seven trials saw a slight decrease in oil production that could be due to recycling of injectate, although the Lodgepole equivalents used for disposal are widely reported to readily take water on a vacuum. A DOWS trial with disposal into a zone below the Bakken/Exshaw shale that provides better separation of disposal and production zones would be useful for comparison.

Other Comparable Fields: This setting is comparable to the Mission Canyon fields in the 
Montana and North Dakota portions of the Williston Basin.

\section{East-Central Alberta Lower Cretaceous Sands}

Seven wells in this setting have had DOWS installations. One trial involved a gravity separation-type DOWS and six involved hydrocyclone-type DOWS.

Geologic and Reservoir Setting: The Lower Cretaceous Mannville Formation is a significant, widespread mixture of marine shales and mixed marine/fluvial sands up to 900 feet thick. The basal Mannville is represented across the western Canada sedimentary basin by the Cadomin-Gething-Dina Formations. In the Wainwright area of east-central Alberta, these fluvial sands are included in the Dina Formation, which is locally a thick sequence of stacked channels. Dina sands are often highly porous, with permeabilities over 1.0 darcy, but individual sand beds are typically thin and separated by shales (Hayes et al. 1994). Oils in the area range from $38^{\circ}$ API gravity at Alliance to $17.5^{\circ}$ in the Hayter well at Chatwin. Many of the Dina traps are stratigraphic permeability barriers, but the three Pinnacle wells are in a structural trap featuring stacked Dina channel sands. Disposal is into highly permeable lower Dina sands that are not in direct hydrologic contact with the producing zone; with this arrangement, these DOWS wells do not presently have to be permitted with the Alberta Energy and Utilities Board as disposal wells. That Board is in the process of considering the need for approval of disposal to the zone of origin.

Production Performance: Table 3 shows the production of oil and water from these wells before and after DOWS installation. Average oil production increased by about $60 \%$ while average water produced to the surface decreased by nearly $80 \%$. Because of high incremental water-handling costs in the area, there is a significant incentive to reduce water volumes reaching the surface. Although post-DOWS installation water production volumes for the PanCanadian wells were not available, all of the other wells in this region showed significant reduction in produced water brought to the surface following DOWS installation. Oil production declined in three wells, but as noted by Matthews et al. (1996), by freeing up surface waterhandling facilities, other wells in the field could be produced at a higher rate. Production and disposal zones are typically quite close together - less than 100 feet in the data that we have - but this does not seem to have caused recycling in any of the tests. The three PanCanadian wells in the Alliance field that have been sold to Pinnacle are very near their economic limit, but the hydrocyclones and pumps are still functioning after nearly three years of operation.

Problems: The Lower Mannville sands have proved to be sensitive to workover stimulations. The Pinnacle-Alliance 06D well suffered significant damage because of use of incompatible fluids during a workover, but this situation has apparently not caused the DOWS to malfunction. In one trial, the oil production rates before and after DOWS installation stayed nearly the same. The three PanCanadian tests in the Provost field all showed problems 
Table 3 - Production Volumes for DOWS Trials in East-Central Alberta Lower Cretaceous Sands

\begin{tabular}{|c|c|c|c|c|c|}
\hline \multirow{3}{*}{ Operator and Well } & \multirow[b]{3}{*}{ Type of DOWS } & \multicolumn{4}{|c|}{ Production (bbl/day to surface) } \\
\hline & & \multicolumn{2}{|c|}{ Pre-DOWS } & \multicolumn{2}{|c|}{ Post-DOWS } \\
\hline & & Oil & Water & Oil & Water \\
\hline Pinnacle-Alliance 7C2 & hydrocyclone & 44 & 380 & 100 & 95 \\
\hline Pinnacle-Alliance 06D & hydrocyclone & 25 & 820 & 100 & 160 \\
\hline Pinnacle-Alliance 07C & hydrocyclone & 38 & 1,200 & 37 & 220 \\
\hline PanCanadian Provost 11c-5 & hydrocyclone & 21 & 690 & 17 & no data \\
\hline PanCanadian Provost 11a2-5 & hydrocyclone & 34 & 979 & 14 & no data \\
\hline PanCanadian Provost 00/16-5 & hydrocyclone & 9.4 & 546 & 16 & no data \\
\hline Talisman Hayter & gravity separator & 25 & 250 & 32 & 25 \\
\hline Average & & 28 & 715 & 45 & 148 \\
\hline
\end{tabular}

due to plugging of the injection zone. Two of the three showed a decrease in oil produced to the surface. Anticipating sanding problems at its Bellshill Lake installation, Petro-Canada chose a well with sufficient history to show stabilization of sand production and has experienced no mechanical problems (McIntosh 1998).

Other Comparable Fields: U.S. formations that are comparable to the Lower Mannville cover most of the western half of the country and include the Dakota, the Woodbine, and the Tuscaloosa. Lower Cretaceous sediments underlie the Great Plains, the Gulf Costal Plain, and adjacent areas. All of these are thick sand-shale packages deposited over a broad shelf where scattered stratigraphic traps can set up large accumulations of oil and gas.

\section{Central Alberta Reef Trend}

Nine wells producing out of Devonian reefs in central Alberta have had DOWS installations. Four trials involved gravity separation-type DOWS and five involved hydrocyclone-type DOWS.

Geologic and Reservoir Setting: These formations are Middle Devonian (Beaverhill Lake Group) or Upper Devonian (Woodbend or Winterburn formations) in age. Lithologically, the producing and disposal zones are dolomitic with vuggy porosity and high permeabilities 
(Odale and Munday 1994; Switzer et al. 1994). The pay zones of Middle and Upper Devonian reef wells are often very thick. Shale or anhydrite intercalations separate different reservoirs within the reef and allow the disposal of salt water into a lower part of the reef mass while still maintaining separation. The vuggy porosity and lack of coherent bedding within the reef give rise to exceptional vertical permeability. This phenomenon may have contributed to the success of the DOWS tools in the reefal production setting, but it also could lead to problems of communication between the production and injection zones.

Production Performance: Table 4 shows the production of oil and water from these wells before and after DOWS installation. The trials have been very successful. Average oil production in hydrocyclone-type DOWS increased by about $150 \%$ while oil production in gravity separator-type DOWS actually decreased slightly. Average water produced to the surface decreased by more than $85 \%$ in both types of DOWS. Two wells in particular yielded exemplary results - the Gulf Canada Fenn-Big Valley well increased oil produced to the surface by almost six times (Peats 1998). The PanCanadian 00/02-09 Bashaw well was singled out by Peachey et al. (1997) as a spectacular success, increasing oil produced to the surface by more than 12 times.

Table 4 - Production Volumes for DOWS Trials in Central Alberta Reef Trends

\begin{tabular}{|c|c|c|c|c|c|}
\hline \multirow[b]{3}{*}{ Operator and Well } & \multirow[b]{3}{*}{ Type of DOWS } & \multicolumn{4}{|c|}{ Production (bbl/day to surface) } \\
\hline & & \multicolumn{2}{|c|}{ Pre-DOWS } & \multicolumn{2}{|c|}{ Post-DOWS } \\
\hline & & Oil & Water & Oil & Water \\
\hline Imperial Redwater \#1-26 & hydrocyclone & 19 & 1,780 & 24 & 59 \\
\hline Anderson 08-17 & hydrocyclone & 176 & 3,648 & 264 & 264 \\
\hline Gulf Canada 02/12-01 & hydrocyclone & 21 & 1,038 & 117 & 217 \\
\hline $\begin{array}{l}\text { PanCanadian 00/07-09 } \\
\text { Bashaw }\end{array}$ & hydrocyclone & 19 & 352 & 62 & 250 \\
\hline $\begin{array}{l}\text { PanCanadian 00/02-09 } \\
\text { Bashaw }\end{array}$ & hydrocyclone & 13 & 428 & 164 & 239 \\
\hline Chevron PNB 14-20 & $\begin{array}{l}\text { gravity } \\
\text { separator }\end{array}$ & 75 & 517 & 84 & 14 \\
\hline Talisman South Sturgeon & $\begin{array}{l}\text { gravity } \\
\text { separator }\end{array}$ & 27 & 932 & 26 & 179 \\
\hline Tristar Sylvan Lake & $\begin{array}{l}\text { gravity } \\
\text { separator }\end{array}$ & 35 & 403 & no data & 57 \\
\hline
\end{tabular}




\begin{tabular}{|l|l|l|l|l|l|}
\hline Crestar Sylvan Lake 00/08 & $\begin{array}{l}\text { gravity } \\
\text { separator }\end{array}$ & 25 & 315 & 2 & 54 \\
\hline Average & & 46 & 1,001 & 93 & 149 \\
\hline
\end{tabular}

The combination of good vertical permeability in the reef rock cycles and horizontal tight zones that typically separate production and disposal zones works to the advantage of DOWS technology. At the Redwater \#1-26 well, Imperial discovered that the good injectivity in the disposal zone became even better over time. Following DOWS installation, the Talisman South Sturgeon well produced about the same amount of oil but with a greatly reduced volume of water brought to the surface. The only trial that has exhibited problems is the Crestar Energy well in the Sylvan Lake field that recycled produced water, probably because the producing zone and disposal zone are separated by only 24 feet in this well. In this case, oil production dropped by more than $90 \%$. Overall, this group of wells stands out as a significant success. Other reef reservoirs would make good candidates for future field trials.

Problems: The Crestar well at Sylvan Lake had mechanical problems; it appears to be recycling water outside of the well casing. The Chevron PNB well in the Drayton Valley field was an extremely unstable well that had been used as both an injection and a producing well on an intermittent cycle. The well was also intermittently gassy, but the DAPS unit seemed to work well.

Other Comparable Fields: The reef setting appears to be quite favorable to the DOWS technology. U.S. reef trends, such as those found in Michigan, Texas, and Colorado, should be investigated for suitable wells.

\section{East Texas Field}

The large East Texas oil field is the site of four DOWS installations, all of which are gravity separation-type DOWS.

Geologic and Reservoir Setting: The East Texas field is a giant stratigraphic trap of thin but widespread mixed marine and fluvial sands of the Upper Cretaceous Woodbine Formation. The total Woodbine sand thickness is approximately 200 feet and is typically composed of wavedominated deltaic sand lenses. The trapping mechanism is stratigraphic at the up-dip erosional edge of the individual strike-oriented sand bodies. The East Texas field produces from the Dexter member, which has an average pay thickness of only 38 feet. The pay sand is often unbroken by permeability barriers. Porosity averages $25 \%$, permeability averages 1.3 darcies, and the oil is $38^{\circ}$ API gravity. The field has a very strong water drive, which has caused some wells in up-dip positions to produce much more oil than was originally in place (Galloway 1983). The East Texas field has been water flooded since 1938, and its excellent vertical and horizontal permeability have lead to near-ideal sweep conditions within the field. Both production and disposal have been into the Woodbine Formation in fairly close proximity. 
Production Performance: Table 5 shows the production of oil and water from these wells before and after DOWS installation. Three of these trials have functioned well with modest percent increases in oil production (although the volume of oil production more than doubled) and about a $40 \%$ decrease in water brought to the surface. The Texaco SU 1040 trial did not perform well, and the pump was pulled early. No data were available for that trial. Oil production increase has been modest because the wells themselves were marginal producers at the start of the trials.

Table 5 - Production Volumes for DOWS Trials in the East Texas Field

\begin{tabular}{|l|l|l|l|l|l|}
\hline \multirow{2}{*}{ Operator and Well } & \multirow{2}{*}{} & \multicolumn{3}{l}{ Production (bbl/day to surface) } \\
\cline { 3 - 6 } & \multirow{2}{*}{ Type of DOWS } & Pre-DOWS & \multicolumn{2}{l|}{ Post-DOWS } \\
\cline { 3 - 6 } & Oil & Water & Oil & Water \\
\hline Texaco Dickson \#17 & gravity separator & 3 & 184 & 10 & 126 \\
\hline Texaco SU 1040 & gravity separator & no data & no data & no data & no data \\
\hline Chevron Shepard \#65 & gravity separator & 7 & 269 & 16.5 & 127 \\
\hline Texaco Ingram & gravity separator & 15 & no data & 26 & 150 \\
\hline Average & & 8 & 226 & 17 & 134 \\
\hline
\end{tabular}

Problems: The DAPS equipment used in East Texas has been prone to problems requiring pulling of the pumps. This problem might be due to the fact that the East Texas installations were some of the earliest of the DAPS tools. The duration of pump life has been varied. Some parts of the field have experienced problems with produced sand, but that did not appear to have caused a problem with the DOWS installations.

Other Comparable Fields: The East Texas field is comparable to the Lower Mannville oil fields of east central Alberta. Both areas are stratigraphic traps on Cretaceous shelves with strong water drives and are high-quality, porous sand reservoirs. Some fields comparable to the Woodbine have stacked reservoirs, making the gravity separation technology a possible avenue to simultaneous production and enhanced oil recovery (EOR) injection wells. In such a DOWS installation, one oil reservoir would produce into the separator, and the injectate would be used to flood another oil reservoir. Such an installation would allow a company to operate a water flood with no injection wells, thereby saving a great deal of capital expense. Up to the present time, however, no wells have been so equipped.

\section{Economic Drivers for DOWS}


Operators are striving to achieve two possible goals through installation of DOWS. The Canadian operators were primarily driven to install DOWS because of water-handling costs. Peachey et al. (1997) report water-handling costs in some areas of western Canada as high as $\$ 3.00$ Canadian/bbl. Such costs create an enormous strain on the profitability of any well producing large volumes of produced water, even if the well also produces large volumes of oil. Most of the Canadian wells are located in areas where production is comparatively new. Few, if any, of these wells have watered out and been converted to disposal wells. This was not the case for most of the U.S. installations, which were in very mature, water-flooded fields, such as East Texas, Salem, or Rangely. Other U.S. installations are in water-poor West Texas, where makeup water for water flooding is at a premium. The U.S. installations are largely aimed at increasing oil production. Marathon, however, tends to agree with the Canadian operators, and has identified the best use of DOWS to be in areas of high water-handling costs (Kintzele 1997).

The potential for cost savings and rapid payback were illustrated in Chapter 2. These examples are confirmed by the data compiled in Appendix A. For example, the average DOWS installed in a well in a carbonate formation increased oil production by $23 \mathrm{bbl} /$ day and decreased water brought to the surface by $1,070 \mathrm{bbl} /$ day. Assuming a sales price for oil of $\$ 11.50 / \mathrm{bbl}$ and a disposal cost for produced water of $\$ 0.30 / \mathrm{bbl}$, such a DOWS could provide an economic advantage of $\$ 585$ per day, or $\$ 17,550$ per month. The cost-effectiveness of a DOWS installation depends on its monthly savings and its ability to remain in service long enough for the installation costs to be paid back. Some, but not all, of the trials reviewed in this report have achieved the requisite longevity.

Most operators were unwilling to share their cost data, so we have had to rely on generic examples such as provided in the previous paragraph. Nevertheless, if candidate wells are carefully selected and the DOWS equipment is properly installed, DOWS offer great potential for being a cost-effective technology.

\section{Experience with Problems}

Injectivity Problems - For the DOWS to function properly, the injection zone must have sufficient permeability and porosity to accept brine at a pressure within the capability of the pump. At least two installations have suffered from low injectivity of the receiving zone; in both cases, inappropriate fluids contacted sensitive sands, which plugged part of the permeability. The Texaco RMOTC and the Pinnacle-Alliance 06D wells experienced low injectivity, but both installations were successful in that the volume of water brought to the surface was decreased and the volume of oil produced increased. In the case of the Pinnacle-Alliance well, the injection zone initially had very high injectivity values; therefore, even with damage, the resulting injectivity was sufficient. In the case of the Texaco well, only moderate volumes of water (approximately $350 \mathrm{bpd}$ ) were being handled, and the injection zone was sufficient. In either case, however, the performance of the well could potentially have been improved in the absence of injectivity problems. 
Isolation Problems - To protect the producing reservoir, the injection zone must be adequately isolated by an integral confining zone and sound cement behind production casing. The installations described in Appendix A have separation between the production zone and the injection zone ranging from 12 to 2,300 feet. Wells with thin separation layers often have problems and wells with thick zones of separation have high pressure differentials to overcome. If isolation is not sufficient, the injectate can migrate into the producing zone and then shortcircuit into the producing perforations. The result will be recycling of the produced water, with oil production rates dropping to nearly zero. Crestar's Sylvan Lake well experienced communication between the producing and injecting zones. The injection and production zones were only 24 feet apart in a fractured carbonate, and oil production decreased from 25 to $2 \mathrm{bpd}$. The Chevron Rangely well may also have experienced recycling, although tests were inconclusive. The DOWS in this well utilized only 30 feet of separation in the Weber sand section.

Plugging Problems - There appears to be a difference of opinion about the susceptibility of the various DOWS tools to plugging by produced sand or fines. Talisman reports that new wells gave them problems with plugging by fines. Talisman now uses the DOWS tools only in established wells with a production history. PanCanadian reports produced sand plugging in its wells at the Provost field. However, this problem appears to have been corrected by installing a desanding system prior to the deoiling hydrocyclone (Danyluk et al. 1998). Wascana reports that the hydrocyclone was damaged by produced sand. Other operators (e.g., Imperial, Gulf Canada, Anderson) did not report problems with plugging.

Corrosion and Scale Problems - Several operators mentioned corrosion and scale as problems. Talisman and Texaco both reported that trials were canceled because of corrosion problems with their DAPS tools.

Design Problems - Only two operators reported problems with tool design. Chevron considered that poor performance at their Rangely trial was due in part to an undersized pump. Southward determined that the DAPS separation chamber in the well's annulus was too short, thereby producing a residence time of only a few seconds in the separation chamber and causing oil to be pumped into the injection zone. In contrast, the DOWS installation in Chevron's Drayton Valley well processed slightly more fluid through the same 5.5-inch casing without experiencing oil loss because it was engineered with a longer separation chamber. 


\section{Chapter 4 - Regulatory Considerations}

Federal Requirements for Injection of Produced Water

The Safe Drinking Water Act directs the U.S. Environmental Protection Agency (EPA) to establish the Underground Injection Control (UIC) program. The UIC program creates five classes of injection wells. Wells used for disposing of produced water or injecting produced water for enhanced oil recovery are considered to be Class II wells. The application, construction, operating, monitoring, and reporting requirements for Class II wells are found in 40 CFR 144 and 146. Some key features of the EPA regulations are highlighted below.

Area of Review (40 CFR 144.55 and 146.6) - Applicants for new Class II injection wells must identify the location of all known wells within the injection well's area of review (a circular area around the injection well) that penetrate the injection zone, or for Class II wells operating over the fracture pressure of the injection formation, all known wells within the area of review penetrating formations affected by the increase in pressure. Applicants must also submit a corrective action plan consisting of such steps or modifications as are necessary to prevent the movement of fluids into USDWs.

Mechanical Integrity (40 CFR 146.8 and 146.23(b)(3)) - Operators must demonstrate that there is no significant leakage in the casing, tubing, or packer of their injection wells, and that there is no significant fluid movement into a USDW through vertical channels adjacent to the well bore. The regulation specifies the types of mechanical integrity test methods that are approved by the EPA. Mechanical integrity must be demonstrated at least every five years.

Plugging and Abandonment (40 CFR $144.52(a)(6)$ and 146.10) - Injection wells that have not been in operation for two years must be plugged and abandoned unless special precautions are taken to avoid endangerment of USDWs. Prior to abandonment, Class II wells must be plugged with cement in a manner that will not allow movement of fluids into or between USDWs.

Construction Requirements (40 CFR 146.22) - All new Class II wells must be sited to inject into a formation that is separated from a USDW by a confining zone that is free of known open faults or fractures within the area of review. Class II wells must be cased and cemented to prevent fluid movement into or between USDWs. The regulations list several criteria that must be considered in determining casing and cementing requirements. Logs and other tests must be conducted during the drilling and construction of new Class II wells, and an interpretation of those logs and tests must be submitted to the regulatory agency. The regulations indicate the types of $\operatorname{logs}$ and tests that are required.

Operating Requirements (40 CFR 146.23(a)) - The operating requirements in UIC Class II permits must specify a maximum injection pressure that will not initiate new fractures or propagate existing fractures in the confining zone adjacent to the USDWs. Injection pressure 
must not cause the movement of fluids into a USDW. Injection into the space between the outermost casing protecting the USDW and the well bore is prohibited.

Monitoring and Reporting Requirements (40 CFR 146.23(b) and (c)) - Operators must monitor the nature of injected fluids, injection pressure, flow rate, and cumulative volume at various frequencies specified in the regulation. Operators must submit at least an annual report of the monitoring results.

\section{$\underline{\text { State Requirements for Injection of Produced Water }}$}

Many states have received authority from EPA to administer the UIC program. States seeking authority to administer the UIC program can seek primacy in two ways. Under $\S 1422$ of the SDWA, states must demonstrate that their state regulations are at least as stringent as those adopted by EPA. To provide greater flexibility for states administering Class II programs, Congress added $\S 1425$ to the SDWA, which requires states seeking delegation to have an underground injection program that meets the following general requirements and represents an effective program to prevent underground injection that endangers drinking water sources:

- $\quad$ Prohibits underground injection unless authorized by permit or rule,

- $\quad$ Prohibits underground injection activities that endanger USDWs,

- $\quad$ Includes inspection, monitoring, recordkeeping, and reporting requirements, and

- $\quad$ Applies to federal agencies and to injection activities conducted on federal and private lands.

Because the $§ 1425$ approval route offers greater flexibility, most states that have obtained UIC primacy have done so that way.

State regulations are similar to, but are not necessarily exact replicas, of federal regulations. This report does not include separate descriptions of the UIC regulations for all oil and gas states. It does describe those portions of state UIC regulations or administrative policies that specifically address DOWS. As of May 1998, only two states (Colorado and Oklahoma) have added DOWS-specific provisions to their UIC regulations. Two other states (Louisiana and Texas) have developed administrative guidelines for DOWS. Kansas has developed proposed regulations but had not finalized them as of early summer 1998. Each of these state regulations are discussed in the following sections.

Colorado - The Colorado Oil and Gas Conservation Commission blended DOWS requirements into their existing regulations rather than adding an entirely new section for DOWS. A simultaneous injection well (the same thing as a well with a DOWS) is defined as "any well in which water produced from oil and gas producing zones is injected into a lower injection zone 
and such water production is not brought to the surface." Differences in regulatory requirements between conventional injection wells and simultaneous injection wells are shown in Table 6 .

Table 6 - Differences in Regulatory Requirements Between Conventional Injection Wells and Simultaneous Injection Wells - Colorado

\begin{tabular}{|c|c|c|}
\hline Item & $\begin{array}{l}\text { Conventional Injection } \\
\text { Wells }\end{array}$ & $\begin{array}{l}\text { Simultaneous Injection } \\
\text { Wells }\end{array}$ \\
\hline $\begin{array}{l}\text { Application must provide } \\
\text { names, addresses, and holdings } \\
\text { of all owners within } 1 / 4 \text { mile of } \\
\text { the proposed well }\end{array}$ & $\begin{array}{l}\text { Both surface and mineral } \\
\text { owners }\end{array}$ & Mineral owners only \\
\hline $\begin{array}{l}\text { Application must include water } \\
\text { analysis of producing formation }\end{array}$ & No & Yes \\
\hline $\begin{array}{l}\text { Application must include a list } \\
\text { of all domestic and irrigation } \\
\text { wells within } 1 / 4 \text { miles of the } \\
\text { proposed well }\end{array}$ & Yes & No \\
\hline $\begin{array}{l}\text { Application must include the } \\
\text { downhole pump setting depth }\end{array}$ & Not applicable & Yes \\
\hline $\begin{array}{l}\text { Application must include a list } \\
\text { of all leases connected directly } \\
\text { by pipelines to the system }\end{array}$ & Yes & No \\
\hline $\begin{array}{l}\text { Applicant must submit a list of } \\
\text { all sources of water, by leases } \\
\text { and by well, to be injected }\end{array}$ & Yes & No \\
\hline $\begin{array}{l}\text { Application must include the } \\
\text { estimated amount of water to be } \\
\text { injected daily }\end{array}$ & $\begin{array}{l}\text { Yes, but must also indicate } \\
\text { the minimum and maximum } \\
\text { amount of water to be } \\
\text { injected daily }\end{array}$ & Yes \\
\hline $\begin{array}{l}\text { Maximum injection pressure } \\
\text { will be set by the Commission } \\
\text { upon approval }\end{array}$ & Yes & $\begin{array}{l}\text { Regulation is silent on this } \\
\text { point }\end{array}$ \\
\hline $\begin{array}{l}\text { Additional mechanical integrity } \\
\text { tests required following the } \\
\text { initial test }\end{array}$ & $\begin{array}{l}\text { At least every five years as } \\
\text { long as the well is used for } \\
\text { fluid injection }\end{array}$ & None required \\
\hline
\end{tabular}




\begin{tabular}{|l|l|l|}
\hline $\begin{array}{l}\text { Reporting of volume of water } \\
\text { injected }\end{array}$ & $\begin{array}{l}\text { Report on the basis of } \\
\text { properly calibrated meter } \\
\text { measurements or tank } \\
\text { measurements of water-level } \\
\text { differences; if water is } \\
\text { transported to an injection } \\
\text { facility by means other than } \\
\text { direct pipeline, measurement } \\
\text { of water is required by a } \\
\text { properly calibrated meter }\end{array}$ & $\begin{array}{l}\text { Report volume of water } \\
\text { produced in addition to } \\
\text { volume of water injected; } \\
\text { report on the basis of } \\
\text { calculated pump volumes, } \\
\text { properly calibrated meter } \\
\text { measurements, or an annual } \\
\text { production test using a } \\
\text { produced water to gas ratio. }\end{array}$ \\
\hline
\end{tabular}

Oklahoma - The Oklahoma Corporation Commission defines simultaneous injection well as "a well that injects or disposes of salt water at the same time it is producing oil and/or gas to the surface." The Corporation Commission added a new section 165:10-5-15, Application for Permit for Simultaneous Injection Well, to its General Rules in July 1996. This section is reprinted below.

"165:10-5-15. Application for permit for simultaneous injection well.

(a) General.

(1) Simultaneous injection of salt water without a valid permit from the Underground Injection Control Department will be subject to a fine of up to $\$ 5,000$ per day of operation.

(2) A simultaneous injection facility shall be inspected by a representative of the commission prior to operation.

(b) Criteria for approval.

(1) Simultaneous injection may be permitted if the following conditions are met and injection will not adversely affect offsetting production nor endanger treatable water.

(A) Injection zone is located below the producing zone in the borehole.

(B) Injection pressure is limited to less than the local fracture gradient.

(C) If injection is by gravity flow, no Area of Review will be required.

(D) If injection is by positive pump pressure, a 1/4 mile Area of Review will be required. If unplugged or mud-plugged boreholes are located within the $1 / 4$ mile radius, the operator of the proposed simultaneous injection well will be required to reconcile these boreholes prior to a permit being issued.

(E) Simultaneous injectors must meet the requirements of 165:10-3-4 as they apply to producing wells.

(F) Simultaneous injectors may be authorized to accept produced water from other wells. The UIC Department will determine on a case-by-case basis whether such a well warrants designation as a simultaneous injector, or whether the well requires a Commission order. 
(2) Required form and attachments. Each application for simultaneous injection shall be submitted to the UIC Department on Form 1015SI in quadruplicate. The forms must be properly completed and signed. Attached to one copy of the application form shall be the following:

(A) Affidavit of mailing a copy of the completed Form 1015SI to each operator of a producing lease within $1 / 2$ mile of the subject well.

(B) Schematic diagram of the well showing all casing and tubing strings, packers, perforations and pumps.

(3) Monitoring, testing and reporting requirements for simultaneous injection wells.

(A) Upon receiving a permit, operator shall file an amended Completion Report Form 1002A within 30 days of recompletion.

(B) Mechanical integrity will be demonstrated by filing annual reports of surface casing pressure, production casing pressure and fluid level.

(C) Annual Report Form 1012 shall be submitted prior to April 1 of each year for the previous calendar year.

(4) If no protest is received within 15 days of the mailing of Form 1015SI, the application shall be submitted for administrative approval. If a protest is received within the protest period, the operator shall, within 30 days, set and give proper notice of a date for hearing on the Pollution Docket before an Administrative Law Judge.

(c) Expiration of the permit. The permit shall expire on its own terms if the subject well is not recompleted or if a revised Form 1002A is not submitted within 180 days from the date on the permit."

Louisiana - In October 1996, the Commissioner of Conservation, Department of Natural Resources, issued a memorandum to district managers that outlined Louisiana's guidelines for handling what he referred to as "simultaneous production/downhole injection" (Carmouche 1996). The memorandum primarily describes the administrative logistics rather than special application, installation, and operational requirements. The requirements pertinent to the application are summarized below.

Applications must be mailed to the District office with copies going to offset operators. The application should include:

- A detailed narrative description of the proposed equipment and installation procedure,

- $\quad$ A copy of Form UIC-2 and the fee,

- $\quad$ A statement that any offset operators who oppose the application should make a written objection within ten days, and 
- $\quad$ A list of the names and addresses of all offset operators having a completion in the producing interval that is the subject of the request and to whom a copy of the application has been sent.

Texas - In June 1997, the Railroad Commission staff developed guidelines for applications and permitting of hydrocyclone-type DOWS (DeLeon 1997). In July 1997, the guidelines were approved by the Railroad Commissioners. The Commission has not adopted formal regulations for DOWS but uses the hydrocyclone-type guidelines to prepare UIC permits (DeLeon 1998). The Texas guidelines are more comprehensive than those of the other states in that they distinguish between four categories of production and injection relationships:

- $\quad$ The production zone is above the injection zone, and both zones are within the same reservoir (P/I - same);

- $\quad$ The production zone is above the injection zone, and the injection zone is in a different reservoir (P/I - different);

- $\quad$ The injection zone is above the production zone, and the surface casing is set and cemented through the entire zone of usable quality groundwater (I/P - cement); and

- $\quad$ The injection zone is above the production zone, and the surface casing is not set and cemented through the entire zone of usable quality groundwater (I/P - no cement).

Applications for all DOWS projects must include a well bore sketch, the current fluid level of formation pressure, and the proposed bottom hole injection pressure. All types of DOWS, except those in category P/I - same, must also submit the proposed water:oil ratio. Table 7 compares the permitting requirements for the four categories of DOWS and conventional injection wells. In addition to the requirements outlined in Table 7, all permits for hydrocyclone-type DOWS must meet the following requirements:

- $\quad$ Average and maximum injection pressures and injected volumes must be determined monthly from transducer readings and must be reported every year on Railroad Commission Form H-10.

- $\quad$ Operators must notify the district office of transducer failure within 24 hours and repair the transducer within three months.

- $\quad$ The bottomhole injection pressure may not exceed a fracture gradient of $1.0 \mathrm{psi} /$ foot at the uppermost perforations.

- $\quad$ Any change in wellbore configuration will require a permit amendment.

Table 7 - Permitting Requirements for Hydrocyclone-Type DOWS in Texas Compared to 
Conventional Injection Wells

\begin{tabular}{|c|c|c|c|c|c|}
\hline \multirow[b]{2}{*}{ Item } & \multirow{2}{*}{$\begin{array}{l}\text { Conventional } \\
\text { Injection } \\
\text { Well }\end{array}$} & \multicolumn{4}{|c|}{ DOWS } \\
\hline & & P/I - Same & $\begin{array}{l}\text { P/I - } \\
\text { Different }\end{array}$ & I/P - Cement & $\begin{array}{l}\mathrm{I} / \mathrm{P} \text { - No } \\
\text { Cement }\end{array}$ \\
\hline $\begin{array}{l}\text { Initial } \\
\text { Mechanical } \\
\text { Integrity Test }\end{array}$ & $\begin{array}{l}\mathrm{PT}^{\mathrm{a}} \\
\text { test in the } \\
\text { range of } \\
200-500 \mathrm{psi}\end{array}$ & $\begin{array}{l}\text { PT or } \mathrm{Ada}^{\mathrm{b}} \\
\text { test at } 200 \mathrm{psi}\end{array}$ & $\begin{array}{l}\text { PT or Ada } \\
\text { test at } 200 \text { psi }\end{array}$ & $\begin{array}{l}\text { PT } \\
\text { test at } 200 \mathrm{psi}\end{array}$ & $\begin{array}{l}\text { PT } \\
\text { test at } 200 \mathrm{psi}\end{array}$ \\
\hline $\begin{array}{l}\text { Subsequent } \\
\text { Mechanical } \\
\text { Integrity } \\
\text { Tests }\end{array}$ & $\begin{array}{l}\text { After each } \\
\text { workover; } \\
\text { every } 5 \text { years } \\
\text { with full } \\
\text { surface } \\
\text { casing, every } \\
\text { year without } \\
\text { surface } \\
\text { casing }\end{array}$ & $\begin{array}{l}\text { After each } \\
\text { workover; at } \\
\text { least every } 10 \\
\text { years }\end{array}$ & $\begin{array}{l}\text { After each } \\
\text { workover; at } \\
\text { least every } 10 \\
\text { years }\end{array}$ & Every 5 years & Every 5 years \\
\hline $\begin{array}{l}\text { Tubing- } \\
\text { Casing } \\
\text { Annulus } \\
\text { Monitoring }\end{array}$ & $\begin{array}{l}\text { Weekly, if } \\
\text { any part of } \\
\text { the } \\
\text { groundwater } \\
\text { is protected } \\
\text { only by } \\
\text { uncemented } \\
\text { casing }\end{array}$ & None & None & $\begin{array}{l}\text { Monthly, if } \\
\text { permitted } \\
\text { injection } \\
\text { pressure is } \\
\text { sufficient to } \\
\text { raise fluids to } \\
\text { groundwater } \\
\text { zones }\end{array}$ & Weekly \\
\hline $\begin{array}{l}\text { Measure } \\
\text { Fluid Level }\end{array}$ & None & Quarterly & Quarterly & None & None \\
\hline $\begin{array}{l}\text { Minimum } \\
\text { Water:Oil } \\
\text { Ratio }\end{array}$ & None & None & $1: 1$ & $1: 1$ & $1: 1$ \\
\hline
\end{tabular}

Source - Base on DeLeon (1997)

${ }^{a}$ The PT (pressure test) is a conventional 200 psi (pounds per square inch) test performed according to the instructions on Railroad Commission Form H-5 with the packer set within 100 feet of the perforations.

${ }^{\mathrm{b}}$ The Ada test is a fluid depression test that may be used in lieu of the PT for wells with production above injection. 
The Railroad Commission has not published any formal guidelines for DAPS-type DOWS. Permits for DAPS-type DOWS are established on a case-by-case basis and typically contain specific testing and monitoring requirements. The DAPS pumps must be sized so that they will not fracture the lower (injection) formation (DeLeon 1998).

Kansas - The Kansas Corporation Commission has developed proposed regulations for simultaneous injection permits but had not finalized these regulations as of early summer 1998 (Snider 1998). Under the proposed regulations, simultaneous injection may be permitted as a Class II injection well if the following provisions are met:

- $\quad$ The injection zone must be located below the producing zone.

- Injection pressure is limited to less than the local injection formation fracture gradient.

- $\quad$ Simultaneous injection wells must be constructed to protect all fresh and usable groundwater and must be contiguously cemented across the injection and producing intervals. Cement above and below the producing and injection intervals must be a minimum of 50 feet. Except in the case of an open hole injection zone, the cement must be continuous from the top of the open hole to 50 feet above the producing interval.

- Mechanical integrity of the casing must be demonstrated before the installation of the simultaneous injection tools.

- $\quad$ Operators must file annual reports of surface casing pressure, production casing pressure, and fluid level.

- $\quad$ Operators must also file Corporation Commission Annual Report Form U3C by March 1 of each year for the previous calendar year. Injected volumes and injection pressures shall be calculated from dynamometer surveys.

Key Regulatory Concerns - Informal discussions with state and federal regulators resulted in the following list of common concerns that regulators are discussing as they issue permits or develop rules for wells with DOWS.

- $\quad$ Should an Area of Review analysis be required?

- Should subsequent mechanical integrity tests be required at intervals after an initial test, and if so, what type of test is appropriate for the various types of DOWS wells?

- $\quad$ Should operating injection rates and pressures be recorded and reported to the agency, and if so, at what frequency? Should rates and pressures be measured in the well with transducers or can they be calculated? 
- Should limits be placed on the injection pressure output of a hydrocyclone based on the fracture gradient of the receiving reservoir?

These concerns are important not only as they relate to environmental protection but also as they affect the economics of DOWS installation. For example, the Texas requirement of directly measuring injection pressures downhole could cost $\$ 30,000$ (Shaw 1998) or higher (Matthews [1998] estimates costs could be greater than \$50,000).

\section{Other Regulatory Considerations}

The UIC program was established by the Safe Drinking Water Act to protect USDWs. In a typical oil well, oil and produced water pass by USDWs on the way to the surface, and USDWs are passed again as produced water is reinjected into a UIC well. In the case of DOWS, the separated produced water is directly injected to a formation near the producing zone without ever coming to the surface or passing through a USDW. DOWS represent a significant reduction of environmental risk over the installation of an individual producing well and injection wells but they create some uncertainty about how they should be classified and regulated.

The EPA's definition of a Class II UIC well [40 CFR 146.5 (b)], which was adopted long before DOWS technology became available, is "wells which inject fluids: (1) which are brought to the surface in connection with conventional oil or natural gas production. ...; (2) for enhanced recovery of oil or natural gas; and ..." Although wells with DOWS installations are very similar to Class II wells, one possible regulatory interpretation is that DOWS are not Class II wells because they are not injecting fluids that have been brought to the surface and are not intentionally being used for enhanced recovery operations. If DOWS are not considered to be Class II wells, they could be treated as Class I UIC nonhazardous wells, Class V UIC wells, or as production wells with no link to the UIC program.

The five states that have already taken some positive action toward regulating DOWS (see above) are treating DOWS as a type of Class II injection well. To get a sense of how other states would treat DOWS, we made an informal telephone survey of state oil and gas programs. Most of the other states have not yet received any requests to use DOWS or have had only one or two requests for experimental trials. There has been no driving force for regulators in those states to develop regulations or permitting guidance or to devote much time to determining how they should best regulate DOWS. The general consensus from the telephone survey is that if DOWS projects are approved, they will be treated the same as other Class II injection wells. One exception to this is Illinois. Illinois has allowed one DOWS trial on an experimental basis. Illinois does not have any specific rules regarding the technology and considers the well as a production well, not a UIC well since the produced water is not being brought to the surface (Bengal 1997).

The EPA has not yet issued any formal federal guidance on how DOWS should be treated. An industry group has held preliminary meetings with EPA Region 8 in Denver about setting up 
an alternate DOWS regulatory system under the auspices of EPA's regulatory reinvention program, Project XL. As of summer 1998, no details are available from these discussions. In addition, the EPA National UIC Technical Workgroup has met to discuss regulatory approaches for DOWS but has not yet released recommendations.

Stuebinger et al. (1997) report that Canadian authorities have been receptive to DAPS and have placed fairly minimal requirements on the regulatory approval process. Typically, when water is disposed to the production formation, the agencies require a letter summary of the project intentions and the method of disposal zone monitoring, if any. When water is disposed to a formation separate from production, the approval process is similar to that for a conventional injection well. The agencies have requested semiannual status reports, including the volume of water injected.

DOWS technology significantly reduces the risks to USDWs, surface water, and soil from produced water. This protection is illustrated in Figure 7, a schematic diagram of two different DOWS installations. DOWS \#1 is depicted with the injection zone lying below the producing zone and with both zones lying beneath the USDW; this is the most common DOWS setup. Because production is above injection, the well is inherently safe. If pressures build up in the injection zone so that fluids begin to migrate vertically above the injection zone, the rising fluids will encounter the producing zone long before they reach the USDW. The producing zone, by virtue of its lower pressure, will act as a sink. Wells equipped with DOWS generally are located in reservoirs that are already substantially depleted, and the sink will absorb any produced water moving upwards toward the surface. For that reason, this type of DOWS should be as safe as a producing well. In fact, if the separator, packer, or bottom pump should fail, the well becomes a producing well.

The Texas Railroad Commission, recognizing the inherent safety of DOWS installations in which the producing zone lies above the injection zone, imposes monitoring requirements that are less stringent than those required for typical Class II wells. As seen in Table 2, the standard pressure mechanical integrity test can be replaced by the less rigorous Ada test, because the section of the annulus down to the packer is a producing well, not an injection well. In addition, follow-up mechanical integrity tests need only be done at least every 10 years rather than every 5 years. Oklahoma and Colorado also agree that this configuration of DOWS is inherently safe and do not require standard mechanical integrity tests on such installations.

DOWS \#2 is depicted with the injection zone lying above the production zone. This type of DOWS configuration has only rarely been used to date. In this configuration, there is no protective sink zone above the injection zone (although, of course, individual wells may be located in geological settings where this condition exists naturally). Therefore, this type of DOWS installation is much like a typical Class II injection well and is treated in a similar fashion by the Railroad Commission. Oklahoma and Colorado also treat wells such as DOWS \#2 as typical Class II wells. For DOWS installations like DOWS \#1 or DOWS \#2 in Figure 7, standard Class II 
well requirements or modified requirements that are less stringent than Class II well requirements appear to be a logical choice.

Many of the state agencies that regulate oil and gas activities have been delegated authority from EPA to administer the UIC Class II program; however, in many states, the authority to administer the Class I and Class V UIC programs is delegated to other state agencies. If DOWS are regulated as Class I or Class $\mathrm{V}$ wells, they will be placed under the jurisdiction of agencies that lack the experience of regulating oil and gas activities. It would be more expeditious and prudent for EPA to modify the definition of Class II wells to incorporate DOWS or to issue guidance to states clarifying that DOWS can be treated as Class II wells. This action would confirm that the current state approach to regulating DOWS is valid and consistent with national policy and would allow agencies experienced in regulating oil and gas activities to regulate DOWS as well.

EPA's recent proposal of UIC Class V regulations (July 29, 1998; 63 FR 40586) may help to resolve this issue. Although the proposed regulations are primarily focused on Class $\mathrm{V}$ wells, EPA also proposes a new definition for Class II wells that is simpler than the existing definition. The proposed definition in new Part 144.80 (b) is: "Class II wells inject fluids connected with oil or natural gas recovery or production or for the storage of liquid hydrocarbons." No mention is made of fluids which are brought to the surface in connection with conventional oil or natural gas production, as is found in the current definition. EPA plans to finalize these regulations by May 2002.

Resolution of how DOWS are to be regulated is an important issue for this emerging technology. Overly rigid regulatory requirements could raise costs to a level at which DOWS development would be inhibited. For example, if a specific state or EPA program requires DOWS wells to be regulated as Class I wells, the regulatory costs could be prohibitive and DOWS would be less likely to be installed. Since DOWS technology results in pollution prevention, any regulatory barriers placed in the way of wider use of DOWS would impose negative environmental impacts. DOWS can also be used to extend the life of producing wells that are approaching the end of their economic life. Consequently, DOWS serve an energy conservation function as well. The authors of this report encourage state oil and gas agencies and the EPA to carefully examine the regulation of DOWS so that overly stringent regulatory requirements do not stand in the way of pollution prevention and energy conservation benefits. 


\section{Chapter 5 - Findings and Conclusions}

Findings

The concept of separating oil from water at the bottom of a well and disposing of the water underground without bringing it to the surface is very attractive. The potential cost savings are large. This report evaluates the feasibility of the DOWS technology by reviewing the types of DOWS currently available to operators and the historical installations of DOWS. The key findings of the report are listed below.

$\square \quad$ There are two basic types of DOWS - those using hydrocyclones to separate oil and water and those relying on gravity separation. Hydrocyclone-type DOWS can handle larger flow volumes than gravity separator-type DOWS but are significantly more expensive. Several alternative designs of DOWS are available from different vendors.

$\square \quad$ Most DOWS installations have been set up with the producing zone above the injection zone. DOWs can potentially be used for waterflooding.

Not all wells will prove to be cost-effective for DOWS installations. The characteristics of wells that are likely to work well with DOWS include, among others, a high water-to-oil ratio, the presence of a suitable injection zone that is isolated from the production zone, compatible water chemistry between the producing and injection zones, and a properly constructed well with good mechanical integrity. DOWS installations in wells that meet these requirements must still remain in good operating condition sufficiently long for the accrued monthly savings to offset the initial purchase costs of the equipment. The track record of existing installations is mixed, with some DOWS remaining in service for more than two years and others failing within a few days. This situation is understandable given that fewer than 40 DOWS have been installed in North America through mid-1998. The technology is new and is still being refined and improved with each successive installation.

This report includes information on 37 DOWS installations in North America. Key statistics from that set of data include:

- More than half of the installations to date have been hydrocyclone-type DOWS (21 compared to16 gravity separator-type DOWS).

- Twenty-seven installations have been in Canada and 10 have been in the United States.

- Seventeen installations were in 5.5-inch casing, 14 were in 7-inch casing, 1 was in 8.625-inch casing, and 5 were unspecified. 
- Twenty of the DOWS installations have been in wells in carbonate formations and 16 in wells in sandstone formations. One trial did not specify the lithology. DOWS appeared to work better in carbonate formations, showing an average increase in oil production of $47 \%$ (compared to $17 \%$ for sandstone formations) and an average decrease in water brought to the surface of $88 \%$ (compared to $78 \%$ for sandstone formations).

- The volume of oil increased in 19 of the trials, decreased in 12 of the trials, stayed the same in 2 trials, and was unspecified in 4 trials. The top three performing hydrocyclonetype wells showed oil production increases ranging from 457 to $1,162 \%$, while one well lost all oil production. The top three gravity separator-type wells showed oil production increases ranging from 106 to $233 \%$, while one well lost all oil production.

- All 29 trials for which both pre-installation and post-installation water production data were provided showed a decrease in water brought to the surface. The decrease ranged from 14 to $97 \%$, with 22 of 29 trials exceeding $75 \%$ reduction in water brought to the surface.

- The data on injectivity and the separation distance between producing and injection formations do not correlate well with the decrease in water volume brought to the surface.

$\square \quad$ Some of the installations experienced problems that impeded the ability of the DOWS to function properly. At least two installations suffered from low injectivity of the receiving zone; in both cases, incompatible fluids contacted sensitive sands, which decreased reservoir permeability. Several installations noted problems of insufficient isolation between the producing and injection zones. If isolation is not sufficient, the injectate can migrate into the producing zone and then short-circuit into the producing perforations. The result will be recycling of the produced water, with oil production rates dropping to nearly zero. Other DOWS have been plugged by fines or sand. Several trials were canceled prematurely due to corrosion and scaling problems. Finally, some of the early installations suffered from poor design features.

The EPA does not now have a formal position on how to regulate DOWS. Four states (Colorado, Oklahoma, Louisiana, and Texas) have developed either regulations or administrative guidelines for DOWS. Those states regulate DOWS with requirements comparable to or less stringent than those for regular Class II injection wells. There is some concern that EPA might decide that DOWS are not covered under the definition of a Class II well, thereby potentially leading to stricter requirements that could hinder future use of DOWS. 


\section{Conclusions}

DOWS have a great potential to save money and reduce the environmental impacts of managing produced water at the surface. The technology is still in its infancy; not all the bugs have been worked out yet. Some trials have been very successful and have paid back costs in a few months. Other trials have failed. The cost of installing DOWS equipment, including the well workover, is substantial. Given the extremely low price of oil in mid-1998, operators have been hesitant to invest in this sort of new equipment. As oil prices rise, DOWS are likely to find wider popularity and use. It is important for EPA and state regulators to develop reasonable regulatory requirements for DOWS in order not to impede their use in the future. 


\section{Chapter 6 - References}

Bengal, L., 1997, personal communication between Bengal, Division of Oil and Gas, Department of Natural Resources, Springfield, IL, and J. Veil, Argonne National Laboratory, Washington, D.C., October 28.

Bowers, B., D.D. Lloyd, P. Schrenkel, and C. Matthews, 1996, "Downhole Application of LiquidLiquid Hydrocyclones," presented at Hydrocyclones ‘96, England, April.

Briffet, M.., 1998, personal communication between Briffet, Wascana Energy, Calgary, Alberta, and B. Langhus, CH2M HILL, Tulsa, OK, March 11.

Browning, B., 1998, faxed data sheet and personal communication between Browning, Tri Link Resources Ltd., Calgary, Alberta, and J. Veil, Argonne National Laboratory, Washington, D.C., May 6.

Carmouche, G.L., 1996, memorandum from Carmouche, Commissioner of Conservation, Louisiana Department of Natural Resources, Baton Rouge, LA, to District Managers, concerning "Simultaneous Production/Downhole Injection," October 31.

Chachula, R.C., C.M. Matthews, and B.R. Peachey, 1996, "Application of Downhole Oil/Water Separation Systems in the Alliance Field," copies of slides used to make the oral presentation of paper SPE \# 35817, presented at the $3^{\text {rd }}$ International Conference on Health, Safety \& Environment in Oil and Gas Exploration \& Production, New Orleans, LA, June 9-12 (the written paper is listed under Matthews et al. [1996])

Chrusch, L.J., 1996, "Downhole Oil and Water Separation - Potential of a New Technology," in the Proceedings of $25^{\text {th }}$ Indonesian Petroleum Association Convention, October.

Collins, R., 1998, personal communication between Collins, Quinn Oilfield Supply Ltd, Red Deer, Alberta, Canada, and J. Veil, Argonne National Laboratory, Washington, D.C., May 21.

Danyluk, T.L., R.C. Chachula, and S.C. Solanki, 1998, "Field Trial of the First Desanding System for Downhole Oil/Water Separation in a Heavy-Oil Application," SPE paper \#49053, presented at the 1998 SPE Annual Technical Conference and Exhibition, New Orleans, LA, September 27-30.

DeLeon, F., 1997, memorandum from DeLeon, Engineering Supervisor, Railroad Commission of Texas, Austin, TX, to D. Schieck, Director, Oil and Gas Division, Railroad Commission of Texas, Austin, TX, June 18.

DeLeon, F., 1998, personal communication between DeLeon, Engineering Supervisor, Railroad Commission of Texas, Austin, TX, and J. Veil, Argonne National Laboratory, Washington, D.C., May 7. 
Elphingstone, G., 1998a, personal communication between Elphingstone, Texaco, Houston, TX, and J. Veil, Argonne National Laboratory, Washington, D.C., May 17.

Elphingstone, G., 1998b, personal communication between Elphingstone, Texaco, Houston, TX, and B. Langhus, CH2M HILL, Tulsa, OK, June 26.

Florence, R., 1998, personal communication between Florence, Alberta Energy and Utilities Board, Calgary, Alberta, and B. Langhus, CH2M HILL, Tulsa, OK, July 2.

Fox, M., 1998, personal communication between Fox, Centrilift, Claremore, OK, and J. Veil, Argonne National Laboratory, Washington, D.C., May 11.

Galloway, W.E., et al., 1983, Major Texas Oil Reservoirs, Bureau of Economic Geology, Austin, TX.

Gray, B., 1998, personal communication between Gray, Imperial Oil, Calgary, Alberta, and B. Langhus, CH2M HILL, Tulsa, OK, January 13.

Grenier, C., 1998, faxed data sheet and personal communication between Grenier, Crestar Energy, Calgary, Alberta, and J. Veil, Argonne National Laboratory, Washington, D.C., May 26.

Grubb, A.D., and D.K. Duvall, 1992, "Disposal Tool Technology Extends Gas Well Life and Enhances Profits," SPE \#24796, presented at the SPE Annual Technical Conference and Exhibition, Washington, D.C., October 4-7.

Hashmi, K.A., H.A. Hamza, and M.T. Thew, 1994, "Liquid-Liquid Hydrocyclone for Deoiling Produced Waters in Heavy Oil Recovery," in Proceedings of the International Petroleum Environmental Conference, Houston, TX, March 2-4.

Hayes, B.J.R., et al., 1994, "Cretaceous Manning Group of the Western Canada Sedimentary Basin," in Geological Atlas of the Western Canada Sedimentary Basin, Mossop, G., et al., eds., Canadian Society of Petroleum Geologists, pp. 317-334.

Hild, G., 1997, personal communication between Hild, Chevron USA, Rangely, CO, and B. Langhus, CH2M HILL, Tulsa, OK, December 30.

Kintzele, M., 1997, personal communication between Kintzele, Marathon, Cody, WY, and B. Langhus, CH2M HILL, Tulsa, OK, December 16.

Kjos, T., S. Sangesland, J.F. Michelet, J. Kleppe, 1995, "Down-Hole Water-Oil Separation and Water Reinjection Through Well Branches," SPE \# 30518, presented at SPE Annual Technical Conference \& Exhibition, Dallas, TX, October 22-25. 
Krug, J., 1998, personal communication between Krug, Petro-Canada, Calgary, Alberta, and B. Langhus, CH2M HILL, Tulsa, OK, July 16.

Levan, M., 1997, personal communication between Levan, Chevron USA, and B. Langhus, CH2M HILL, Tulsa, OK, December 12.

Lockyer, C., 1998, personal communications between Lockyer, Chevron Canada, Calgary, Alberta, and B. Langhus, CH2M HILL, Tulsa, OK, July, 14.

Matthews, C., 1998, written comments submitted by Matthews, C-FER Technologies Inc., Edmonton, Alberta, Canada, to J. Veil, Argonne National Laboratory, Washington, D.C., November 12.

Matthews, C.M., R. Chachula, B.R. Peachey, and S.C. Solanki, 1996, “Application of Downhole Oil/Water Separation Systems in the Alliance Field," SPE \# 35817, presented at the $3^{\text {rd }}$ International Conference on Health, Safety \& Environment in Oil and Gas Exploration \& Production, New Orleans, LA, June 9-12.

McIntosh, G., 1998, personal communication between McIntosh, Petro-Canada, Ft. St. John, British Columbia, and B. Langhus, CH2M HILL, Tulsa, OK, July 21.

McKinzie, H., G. Graves, L. Stuebinger, and G. Elphingstone, 1998, "If You Don't Mix It, You Don't Have to Separate It,"1st North American Conference on Multiphase Technology, Technology from the Arctic to the Tropics, sponsored by the BHR Group, Banff, Canada, June $10-11$.

Murphy, D., 1998, personal communication between Murphy, Texaco, Salem, IL, and B. Langhus, CH2M HILL, Tulsa, OK, March 4.

Naylor, J., 1998a, faxed table and personal communication between Naylor, REDA Pump, Bartlesville, OK, and J. Veil, Argonne National Laboratory, Washington, D.C., May 12.

Naylor, J., 1998b, personal communication between Naylor, REDA Pump, Bartlesville, OK, and B. Langhus, CH2M HILL, Tulsa, OK, February 6.

Noonan, S., 1998, personal communication between Noonan, Chevron USA, Houston, TX, and B. Langhus, CH2M HILL, Tulsa, OK, June 18.

Odale, H.S. and R.J. Munday, 1994, "Devonian Beaverhill Lake Group of the Western Canada Sedimentary Basin," in Geological Atlas of the Western Canada Sedimentary Basin, Mossop, G., et al., eds., Canadian Society of Petroleum Geologists, pp.149-164. 
Peachey, B.R., and C.M. Matthews, 1994, "Downhole Oil/Water Separator Development," Journal of Canadian Petroleum Technology, 33(7): 17-21.

Peachey, B.R., S. Solanki, T. Zahacy, and K. Piers, 1997, "Downhole Oil/Water Separation Moves into High Gear," CIM Paper 97-91, presented at the 48th Annual Technical Meeting of the Petroleum Society, Calgary, Alberta, Canada, June 8-11.

Peats, A., 1998, personal communication between Peats, Gulf Canada, Calgary, Alberta, and B. Langhus, CH2M HILL, Tulsa, OK, January 21.

Peats, A., and P. Schrenkel, 1997, "Application of ESP Oil Water Separation System in the Swan Hills Unit One Field - A Case Study," SPE \# 39079, presented at the SPE Electric Submersible Pump Workshop, Houston, April 30.

Poythress, M., 1998, faxed table and personal communication between Poythress, Dresser Oil Tools, Houston, TX, and J. Veil, Argonne National Laboratory, Washington, D.C., May 12.

Reid, B., 1998, emailed data sheet and personal communication between Reid, Talisman Energy Inc., Carlyle, Saskatchewan, and J. Veil, Argonne National Laboratory, Washington, D.C., April 2.

Richards, B.C., et al., 1994, "Carboniferous Strata of the Western Canada Sedimentary Basin," in Geological Atlas of the Western Canada Sedimentary Basin, Mossop, G., et al., eds., Canadian Society of Petroleum Geologists, pp. 221-250.

Roberts, R., 1998, personal communication between Roberts, Chevron, Kilgore, TX, and B. Langhus, CH2M-Hill, Tulsa, OK, April 9.

Rogers, D., 1997, personal communications between Rogers, Santa Fe Energy, Midland, TX, and B. Langhus, CH2M HILL, Tulsa, OK, December 29.

Scharrer, J., 1998, faxed data sheet and personal communication between Scharrer, Richland Petroleum, Calgary, Alberta, and J. Veil, Argonne National Laboratory, Washington, D.C., May 20.

Schrenkel, P.J., 1997, "Joint Industry Development of the Downhole Oil Water Separation System - Field Case Study," SPE \# 37453, presented at the 1997 SPE Production Operations Symposium, Oklahoma City, OK, March 9-11.

Shaw, C., 1998a, "Frequently Asked Questions about HydroSep," unpublished document distributed by Shaw, Centrilift, Claremore, OK, at a U.S. Department of Energy workshop on simultaneous injection, Tulsa, OK, March 6. 
Shaw, C., 1998b, personal communications between Shaw, Centrilift, Claremore, OK, and B. Langhus, CH2M HILL, Tulsa, OK, July.

Snider, A., 1998, personal communication between Snider, UIC Supervisor, Kansas Corporation Commission, Wichita, KS, and J. Veil, Argonne National Laboratory, Washington, D.C., May 7.

Sobie, S., and C. Matthews, 1997, "Talisman Application Experience with Downhole Oil/Water Separation Systems in Southeast Saskatchewan," presented at Canadian Section Society of Petroleum Engineers/Petroleum Society of CIM One-Day Conference of Horizontal Well Technology, November 12.

Solanki, S.C., T.A. Zahacy, W.D. Roggensack, B.R. Peachey, and J. Mann, 1996, "Downhole Oil/Water Separation Systems (AQWANOT ${ }^{\mathrm{TM}}$ ) Joint Industry Project," presented at SPE Electric Submersible Pump Workshop, Houston, TX, May 1-3.

Stuebinger, L., 1998, personal communication between Stuebinger, Texaco, Denver, CO, and B. Langhus, CH2M HILL, Tulsa, OK, July 15.

Stuebinger, L., K. Bowlin, J. Wright, M. Poythress, B. Watson, 1997, “Dual Injection and Lifting Systems: Rod Pumps," SPE \# 38790, presented at the SPE Annual Technical Conference and Exhibition, San Antonio, TX, October 5-8.

Switzer, S.B., et al., 1994, "Devonian Woodbend Winterburn Strata of the Western Canada Sedimentary Basin," in Geological Atlas of the Western Canada Sedimentary Basin, Mossop, G. et al., eds., Canadian Society of Petroleum Geologists, pp. 165-202.

Wakim, P.G., 1987, “API 1985 Production Waste Survey, Statistical Analysis and Survey Results," American Petroleum Institute, Washington, D.C., October.

Wright, J., 1998, personal communications between Wright, Talisman Energy, Calgary, Alberta, and B. Langhus, CH2M HILL, Tulsa, OK, March. 


\section{Appendix A - Data from DOWS Installations}

Table A-1: Hydrocyclone-Type DOWS - Performance Data

\begin{tabular}{|c|c|c|c|c|c|c|c|c|c|}
\hline Operator and Well Name & Field & $\begin{array}{c}\text { State/ } \\
\text { Province }\end{array}$ & Type of DOWS & $\begin{array}{c}\text { Pre- } \\
\text { DOWS } \\
\text { Oil (bpd) }\end{array}$ & $\begin{array}{c}\text { Pre- } \\
\text { DOWS } \\
\text { Water } \\
\text { (bpd) }\end{array}$ & $\begin{array}{c}\text { Post- } \\
\text { DOWS } \\
\text { Oil (bpd) }\end{array}$ & $\begin{array}{l}\text { Post-DOWS } \\
\text { Water (bpd) }\end{array}$ & $\begin{array}{c}\% \\
\text { Increase } \\
\text { in Oil }\end{array}$ & $\begin{array}{c}\% \\
\text { Decrease } \\
\text { in Water }\end{array}$ \\
\hline Imperial Redwater \#1-26 & Redwater & Alberta & Aqwanot $^{\mathrm{TM}}$ & 19 & 1,780 & 24 & 59 & 26 & 97 \\
\hline $\begin{array}{l}\text { Pinnacle-Alliance (originally } \\
\text { PanCanadian) } 7 \mathrm{C} 2\end{array}$ & Alliance & Alberta & Aqwanot ${ }^{\mathrm{TM}}$ & 44 & 380 & 100 & 95 & 127 & 75 \\
\hline $\begin{array}{l}\text { Pinnacle-Alliance (originally } \\
\text { PanCanadian) 06D }\end{array}$ & Alliance & Alberta & Aqwanot $^{\mathrm{TM}}$ & 25 & 820 & 100 & 160 & 300 & 80 \\
\hline $\begin{array}{l}\text { Pinnacle-Alliance (originally } \\
\text { PanCanadian) 07C }\end{array}$ & Alliance & Alberta & Aqwanot $^{\mathrm{TM}}$ & 38 & 1,200 & 37 & 220 & -3 & 82 \\
\hline PanCanadian 00/11C-05 & Provost & Alberta & Aqwanot ${ }^{\mathrm{TM}}$ & 21 & 690 & 17 & & -19 & \\
\hline PanCanadian 00/11A2-05 & Provost & Alberta & Aqwanot $^{\mathrm{TM}}$ & 34 & 979 & 14 & & -59 & \\
\hline PanCanadian 00/16-05 & Provost & Alberta & Aqwanot $^{\mathrm{TM}}$ & 9.4 & 546 & 16 & & 70 & \\
\hline PanCanadian 00/02-09 & Bashaw & Alberta & Aqwanot $^{\mathrm{TM}}$ & 13 & 428 & 164 & 239 & 1,162 & 44 \\
\hline Talisman Energy & & & Aqwanot $^{\mathrm{TM}}$ & 6 & 629 & 39 & 21 & 550 & 97 \\
\hline Anderson 08-17 & $\begin{array}{l}\text { Swan Hills } \\
\text { Unit \#1 }\end{array}$ & Alberta & Aqwanot $^{\mathrm{TM}}$ & 176 & 3,648 & 264 & 264 & 50 & 93 \\
\hline $\begin{array}{l}\text { Talisman Energy Creelman } \\
3 \mathrm{c} 7-12 / \mathrm{dB}\end{array}$ & Creelman & Saskatchewan & Aqwanot $^{\mathrm{TM}}$ & 113 & 2,516 & 277 & 126 & 145 & 95 \\
\hline Chevron Fee 153X & Rangely & Colorado & Aqwanot ${ }^{\mathrm{TM}}$ & 45 & 1,400 & 32 & 500 & -29 & 64 \\
\hline
\end{tabular}




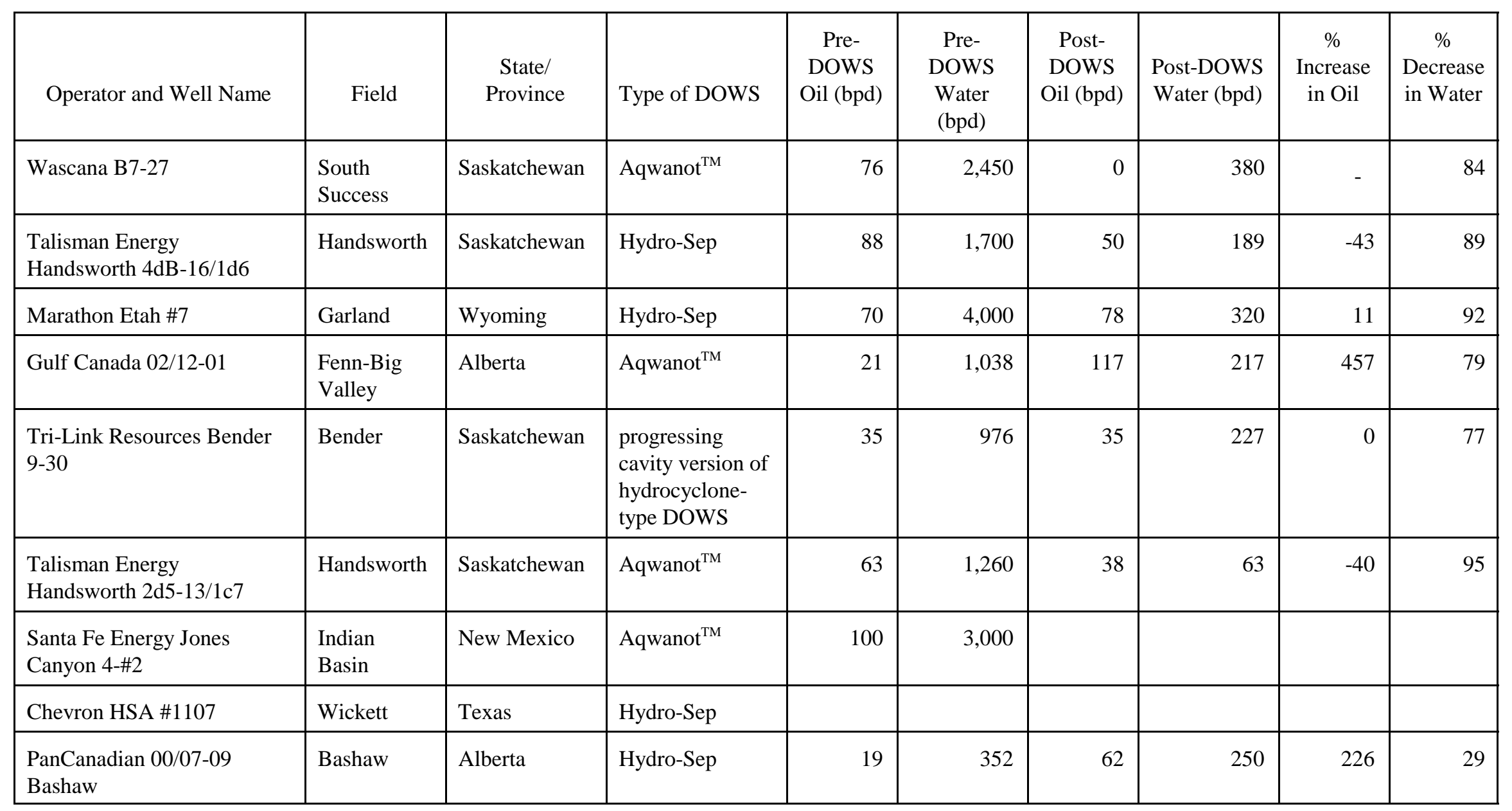


Table A-2: Hydrocyclone-Type DOWS - Well Data

\begin{tabular}{|c|c|c|c|c|c|c|c|}
\hline Operator and Well Name & $\begin{array}{l}\text { Casing Size } \\
\text { (inches) }\end{array}$ & $\begin{array}{l}\text { Production } \\
\text { Formation }\end{array}$ & Lithology & $\begin{array}{l}\text { Injection } \\
\text { Formation }\end{array}$ & $\begin{array}{l}\text { Injectivity } \\
\text { (bpd/psi) }\end{array}$ & $\begin{array}{l}\text { Injection Pressure } \\
\text { Differential (psi) }\end{array}$ & $\begin{array}{l}\text { Separation Between } \\
\text { Production and Injection } \\
\text { Formations (feet) }\end{array}$ \\
\hline Imperial Redwater \#1-26 & 7 & Devonian D-3 & Carbonate & Devonian D-3 & & & \\
\hline $\begin{array}{l}\text { Pinnacle-Alliance (originally } \\
\text { PanCanadian) } 7 \mathrm{C} 2\end{array}$ & 5.5 & Ellerslie-Dina & Sandstone & Dina & 20 & 0 & 43 \\
\hline $\begin{array}{l}\text { Pinnacle-Alliance (originally } \\
\text { PanCanadian) 06D }\end{array}$ & 5.5 & Ellerslie-Dina & Sandstone & Dina & 2 & 0 & 73 \\
\hline $\begin{array}{l}\text { Pinnacle-Alliance (originally } \\
\text { PanCanadian) 07C }\end{array}$ & 5.5 & Ellerslie-Dina & Sandstone & Dina & 20 & 0 & 60 \\
\hline PanCanadian 00/11C-05 & 5.5 & Dina & Sandstone & & & & \\
\hline PanCanadian 00/11A2-05 & 7 & Dina & Sandstone & & & & \\
\hline Anderson $08-17$ & 7 & $\begin{array}{l}\text { Beaverhill } \\
\text { Lake }\end{array}$ & Carbonate & Beaverhill Lake & 21 & 0 & 23 \\
\hline $\begin{array}{l}\text { Talisman Energy Creelman } \\
3 \mathrm{c} 7-12 / \mathrm{dB}\end{array}$ & 7 & Alida & Carbonate & Alida & & 0 & \\
\hline Chevron Fee 153X & 7 & $\begin{array}{l}\text { Weber Zone } \\
\quad 1 \& 3\end{array}$ & Sandstone & Weber Zone 5 & & 0 & 30 \\
\hline Wascana B7-27 & 7 & Upper Rosary & Sandstone & Lower Rosary & very high & & 12 \\
\hline
\end{tabular}




\begin{tabular}{|c|c|c|c|c|c|c|c|}
\hline Operator and Well Name & $\begin{array}{l}\text { Casing Size } \\
\text { (inches) }\end{array}$ & $\begin{array}{l}\text { Production } \\
\text { Formation }\end{array}$ & Lithology & $\begin{array}{l}\text { Injection } \\
\text { Formation }\end{array}$ & $\begin{array}{l}\text { Injectivity } \\
(\mathrm{bpd} / \mathrm{psi})\end{array}$ & $\begin{array}{l}\text { Injection Pressure } \\
\text { Differential (psi) }\end{array}$ & $\begin{array}{l}\text { Separation Between } \\
\text { Production and Injection } \\
\text { Formations (feet) }\end{array}$ \\
\hline Marathon Etah \#7 & 8.625 & Madison & Carbonate & Madison & 20 & 300 & 48 \\
\hline Gulf Canada 02/12-01 & 7 & Nisku D-2 & Carbonate & Nisku D-3 & 23 & 0 & 148 \\
\hline $\begin{array}{l}\text { Talisman Energy } \\
\text { Handsworth 2d5-13/1c7 }\end{array}$ & 7 & Alida & Carbonate & Blairmore & 43 & & \\
\hline $\begin{array}{l}\text { Santa Fe Energy Jones } \\
\text { Canyon 4-\#2 }\end{array}$ & 7 & Cisco-Canyon & Carbonate & $\begin{array}{l}\text { Devonian \& } \\
\text { Montoya }\end{array}$ & & 212 & 2,300 \\
\hline
\end{tabular}


Table A-3: Hydrocyclone-Type DOWS - Additional Information

\begin{tabular}{|c|c|c|c|c|}
\hline Operator and Well Name & $\begin{array}{c}\text { Trial Starting } \\
\text { Date }\end{array}$ & $\begin{array}{l}\text { Trial Ending } \\
\text { Date }\end{array}$ & Comments & Source of Information ${ }^{a}$ \\
\hline Imperial Redwater \#1-26 & $7 / 94$ & $1 / 95$ & Scale problems. & Gray (1998) \\
\hline $\begin{array}{l}\text { Pinnacle-Alliance (originally } \\
\text { PanCanadian) } 7 \mathrm{C} 2\end{array}$ & $7 / 95$ & & & Matthews et al. (1996) \\
\hline $\begin{array}{l}\text { Pinnacle-Alliance (originally } \\
\text { PanCanadian) 06D }\end{array}$ & $8 / 95$ & & & Matthews et al. (1996) \\
\hline $\begin{array}{l}\text { Pinnacle-Alliance (originally } \\
\text { PanCanadian) } 07 \mathrm{C}\end{array}$ & $9 / 95$ & & & Matthews et al. (1996) \\
\hline PanCanadian 00/11C-05 & $12 / 95$ & & Problems with sand plugging. & Florence (1998) \\
\hline PanCanadian 00/11A2-05 & $12 / 95$ & & Problems with sand plugging. & Florence (1998) \\
\hline PanCanadian 00/16-05 & $1 / 96$ & & Problems with sand plugging. & Florence (1998) \\
\hline PanCanadian 00/02-09 & $5 / 96$ & & Problems with $\mathrm{H}_{2} \mathrm{~S}$ and scale. & Florence (1998) \\
\hline Talisman Energy & $5 / 96$ & & & Naylor (1998b) \\
\hline Anderson 08-17 & $7 / 96$ & & Problems with well bore and scale formation. & Peats (1998) \\
\hline $\begin{array}{l}\text { Talisman Energy Creelman } \\
3 \mathrm{c} 7-12 / \mathrm{dB}\end{array}$ & $8 / 96$ & & & $\begin{array}{l}\text { Sobie and Matthews } \\
\text { (1997) }\end{array}$ \\
\hline Chevron Fee 153X & $8 / 96$ & & May have been recycling water? Undersized pump. & Hild (1998) \\
\hline Wascana B7-27 & $5 / 97$ & $11 / 97$ & Produced sand damaged the hydrocyclone. & Briffet (1998) \\
\hline
\end{tabular}




\begin{tabular}{|c|c|c|c|c|}
\hline Operator and Well Name & $\begin{array}{c}\text { Trial Starting } \\
\text { Date }\end{array}$ & $\begin{array}{l}\text { Trial Ending } \\
\text { Date }\end{array}$ & Comments & Source of Information a \\
\hline $\begin{array}{l}\text { Talisman Energy } \\
\text { Handsworth 4dB-16/1d6 }\end{array}$ & $4 / 97$ & & & $\begin{array}{l}\text { Sobie and Matthews } \\
\text { (1997) }\end{array}$ \\
\hline Marathon Etah \#7 & $6 / 97$ & & Did not install check valve. & Kintzele (1997) \\
\hline Gulf Canada 02/12-01 & $7 / 97$ & & & Peats (1998) \\
\hline $\begin{array}{l}\text { Tri-Link Resources Bender } \\
9-30\end{array}$ & $10 / 97$ & $3 / 98$ & Pulled DOWS because of failure in transfer tube. & Browning (1998) \\
\hline $\begin{array}{l}\text { Talisman Energy } \\
\text { Handsworth 2d5-13/1c7 }\end{array}$ & $8 / 97$ & & Capillary tube got creased. & $\begin{array}{l}\text { Sobie and Matthews } \\
\text { (1997) }\end{array}$ \\
\hline $\begin{array}{l}\text { Santa Fe Energy Jones } \\
\text { Canyon 4-\#2 }\end{array}$ & & & Permitted. & Rogers (1997) \\
\hline Chevron HSA \#1107 & $7 / 98$ & & Permit assigned, waiting on tools. & Noonan $(1998$ \\
\hline $\begin{array}{l}\text { PanCanadian 00/07-09 } \\
\text { Bashaw }\end{array}$ & $11 / 97$ & & & Florence (1998) \\
\hline
\end{tabular}

${ }^{a}$ References cited in this table are listed in Chapter 6. 
Table A-4: Gravity Separator-Type DOWS - Performance Data

\begin{tabular}{|c|c|c|c|c|c|c|c|c|c|}
\hline Operator and Well Name & Field & $\begin{array}{c}\text { State/ } \\
\text { Province }\end{array}$ & $\begin{array}{l}\text { Type of } \\
\text { DOWS }\end{array}$ & $\begin{array}{c}\text { Pre- } \\
\text { DOWS } \\
\text { Oil (bpd) }\end{array}$ & $\begin{array}{c}\text { Pre- } \\
\text { DOWS } \\
\text { Water } \\
\text { (bpd) }\end{array}$ & $\begin{array}{c}\text { Post- } \\
\text { DOWS } \\
\text { Oil (bpd) }\end{array}$ & $\begin{array}{l}\text { Post-DOWS } \\
\text { Water (bpd) }\end{array}$ & $\begin{array}{c}\% \\
\text { Increase } \\
\text { in Oil }\end{array}$ & $\begin{array}{c}\% \\
\text { Decrease } \\
\text { in Water }\end{array}$ \\
\hline Texaco Dickson \#17 & East Texas & Texas & DAPS & 3 & 184 & 10 & 126 & 233 & 32 \\
\hline Texaco SU 1040 & Levelland & Texas & DAPS & & & & & & \\
\hline $\begin{array}{l}\text { Talisman Energy Tidewater } \\
\text { Parkman 4-27 }\end{array}$ & Parkman & Saskatchewan & DAPS & 16 & 252 & 33 & 139 & 106 & 45 \\
\hline Texaco Salem \#85-40 & Salem & Illinois & DAPS & 6 & 655 & 6 & 150 & 0 & 77 \\
\hline Chevron Shepard \#65 & East Texas & Texas & DAPS & 7 & 269 & 16.5 & 127 & 136 & 53 \\
\hline Texaco RMOTC 77 Ax20 & RMOTC & Wyoming & DAPS & 5 & 190 & 10 & 38 & 100 & 80 \\
\hline Talisman Energy Hayter & Chatwin & Alberta & DAPS & 25 & 250 & 32 & 25 & 28 & 90 \\
\hline Richland Parkman 1-17 & Parkman & Saskatchewan & DAPS & 20 & 220 & 15 & 190 & -25 & 14 \\
\hline Chevron PNB 14-20 & Drayton Valley & Alberta & DAPS & 75 & 517 & 84 & 14 & 12 & 97 \\
\hline $\begin{array}{l}\text { Talisman Energy South } \\
\text { Sturgeon }\end{array}$ & Grande Prairie & Alberta & DAPS & 27 & 932 & 26 & 179 & -4 & 81 \\
\hline Petro-Canada Utik 13-21 & Utikuma & Alberta & DAPS & 8 & 451 & 10 & 63 & - & 86 \\
\hline Texaco Ingram & East Texas & Texas & DAPS & 15 & & 26 & 150 & 73 & \\
\hline Tristar & Sylvan Lake & Alberta & DAPS & 35 & 403 & & 57 & & 86 \\
\hline Southward 11-13 & Carlile & Saskatchewan & DAPS & 24.5 & 458 & 16 & & -35 & \\
\hline Petro-Canada E4-10-16 & Bellshill Lake & Alberta & Q-Sep-G & 30 & 470 & 38 & 61 & 27 & 87 \\
\hline
\end{tabular}




\begin{tabular}{|c|c|c|c|c|c|c|c|c|c|}
\hline Operator and Well Name & Field & $\begin{array}{c}\text { State/ } \\
\text { Province }\end{array}$ & $\begin{array}{l}\text { Type of } \\
\text { DOWS }\end{array}$ & $\begin{array}{c}\text { Pre- } \\
\text { DOWS } \\
\text { Oil (bpd) }\end{array}$ & $\begin{array}{c}\text { Pre- } \\
\text { DOWS } \\
\text { Water } \\
\text { (bpd) }\end{array}$ & $\begin{array}{c}\text { Post- } \\
\text { DOWS } \\
\text { Oil (bpd) }\end{array}$ & $\begin{array}{l}\text { Post-DOWS } \\
\text { Water (bpd) }\end{array}$ & $\begin{array}{c}\% \\
\text { Increase } \\
\text { in Oil }\end{array}$ & $\begin{array}{c}\% \\
\text { Decrease } \\
\text { in Water }\end{array}$ \\
\hline
\end{tabular}


Table A-5: Gravity Separator-Type DOWS - Well Data

\begin{tabular}{|c|c|c|c|c|c|c|c|}
\hline Operator and Well Name & $\begin{array}{l}\text { Casing Size } \\
\text { (inches) }\end{array}$ & $\begin{array}{l}\text { Production } \\
\text { Formation }\end{array}$ & Lithology & $\begin{array}{l}\text { Injection } \\
\text { Formation }\end{array}$ & $\begin{array}{l}\text { Injectivity } \\
\text { (bpd/psi) }\end{array}$ & $\begin{array}{c}\text { Injection Pressure } \\
\text { Differential (psi) }\end{array}$ & $\begin{array}{c}\text { Separation Between } \\
\text { Production and Injection } \\
\text { Formations (feet) }\end{array}$ \\
\hline Texaco Dickson \#17 & 7 & Woodbine & Sandstone & & & & \\
\hline Texaco SU 1040 & & & Sandstone & & & & \\
\hline $\begin{array}{l}\text { Talisman Energy Tidewater } \\
\text { Parkman } 4-27\end{array}$ & 5.5 & Tilston & Carbonate & Lower Tilston & 6 & 0 & \\
\hline Texaco Salem \#85-40 & 5.5 & Salem & Carbonate & Devonian & & & 1,137 \\
\hline Chevron Shepard \#65 & 5.5 & Woodbine & Sandstone & Woodbine & & 0 & 71 \\
\hline Texaco RMOTC 77 Ax20 & 5.5 & $\begin{array}{l}\text { 2nd Wall } \\
\text { Creek }\end{array}$ & Sandstone & 3rd Wall Creek & & & 240 \\
\hline Talisman Energy Hayter & & & Sandstone & & & & \\
\hline Richland Parkman 1-17 & 5.5 & Tilston & Carbonate & Souris River & 13 & 40 & 151 \\
\hline Chevron PNB 14-20 & 5.5 & Nisku D2 & Carbonate & Nisku D3 & & & \\
\hline $\begin{array}{l}\text { Talisman Energy South } \\
\text { Sturgeon }\end{array}$ & & & Carbonate & & & & \\
\hline Petro-Canada Utik 13-21 & 5.5 & Keg River & Sandstone & Keg River & & & 46 \\
\hline Texaco Ingram & 7 & Woodbine & Sandstone & & & & \\
\hline Tristar & & & Carbonate & & & & \\
\hline Southward 11-13 & 5.5 & Tilston & Carbonate & Souris River & & & \\
\hline Petro-Canada E4-10-16 & 7 & Basal Quartz & Sandstone & Basal Quartz & & 100 & 81 \\
\hline $\begin{array}{l}\text { Crestar Energy Ranchman } \\
\text { Sylvan Lake 00/08 }\end{array}$ & 5.5 & Pekisko & Carbonate & Pekisko & & & 24 \\
\hline
\end{tabular}


Table A-6: Gravity Separator-Type DOWS - Additional Information

\begin{tabular}{|c|c|c|c|c|}
\hline Operator and Well Name & $\begin{array}{c}\text { Trial } \\
\text { Starting } \\
\text { Date }\end{array}$ & $\begin{array}{c}\text { Trial } \\
\text { Ending } \\
\text { Date }\end{array}$ & Comments & Source of Information a \\
\hline Texaco Dickson \#17 & $10 / 95$ & & Shut in. & Elphingstone (1998b) \\
\hline Texaco SU 1040 & $2 / 96$ & & Pulled early. & Elphingstone (1998b) \\
\hline $\begin{array}{l}\text { Talisman Energy } \\
\text { Tidewater Parkman 4-27 }\end{array}$ & $7 / 96$ & $5 / 97$ & Corrosion problems to pump and tubing. & Wright (1998) \\
\hline Texaco Salem \#85-40 & $8 / 96$ & $4 / 97$ & Pumps damaged by corrosion. & Murphy (1998) \\
\hline Chevron Shepard \#65 & $9 / 96$ & & Unit is currently due for a workover but has functioned well. & $\begin{array}{l}\text { Noonan (1998); } \\
\text { Roberts (1998) }\end{array}$ \\
\hline Texaco RMOTC 77 Ax20 & 2/97 & $3 / 97$ & Injection zone damaged during a workover. & Stuebinger (1998) \\
\hline Talisman Energy Hayter & 2/97 & & & Wright (1998) \\
\hline Richland Parkman 1-17 & $1 / 97$ & & Immediately after installation, well produced $35 \mathrm{bpd}$ oil and $160 \mathrm{bpd}$ water. & Scharrer (1998) \\
\hline Chevron PNB 14-20 & $5 / 97$ & $8 / 97$ & Well was very unstable and gassy; DAPS worked well. & Lockyer (1998) \\
\hline $\begin{array}{l}\text { Talisman Energy South } \\
\text { Sturgeon }\end{array}$ & $5 / 97$ & & & Wright (1998) \\
\hline Petro-Canada Utik 13-21 & $6 / 97$ & $10 / 97$ & After two days, DAPS stopped working. DAPS was set above the fluid level. & Krug (1998) \\
\hline Texaco Ingram & $7 / 97$ & & & Elphingstone (1998b) \\
\hline Tristar & $7 / 97$ & & Company out of business; disposition of well is unknown. & Poythress (1998) \\
\hline Southward 11-13 & $1 / 98$ & $3 / 98$ & Residence time in separation chamber was too short; oil lost into disposal zone. & Poythress (1998) \\
\hline Petro-Canada E4-10-16 & $5 / 97$ & $11 / 97$ & Worked very well; sold lease. & McIntosh (1998) \\
\hline $\begin{array}{l}\text { Crestar Energy Ranchman } \\
\text { Sylvan Lake 00/08 }\end{array}$ & $8 / 97$ & $3 / 98$ & Water is recycling; separation of zones is only 24 feet in a fractured carbonate. & Grenier (1998) \\
\hline
\end{tabular}




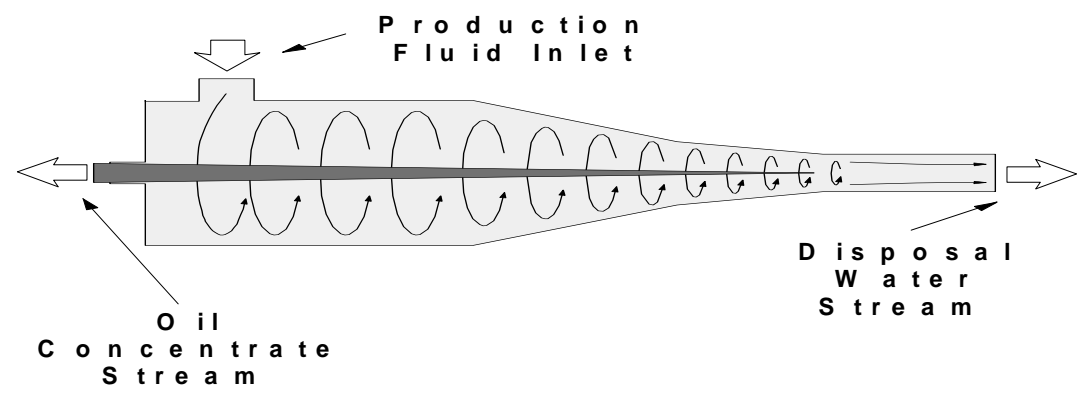

Fig. 1 - Schematic drawing of a hydrocyclone. Reprinted from Schrenkel (1997).

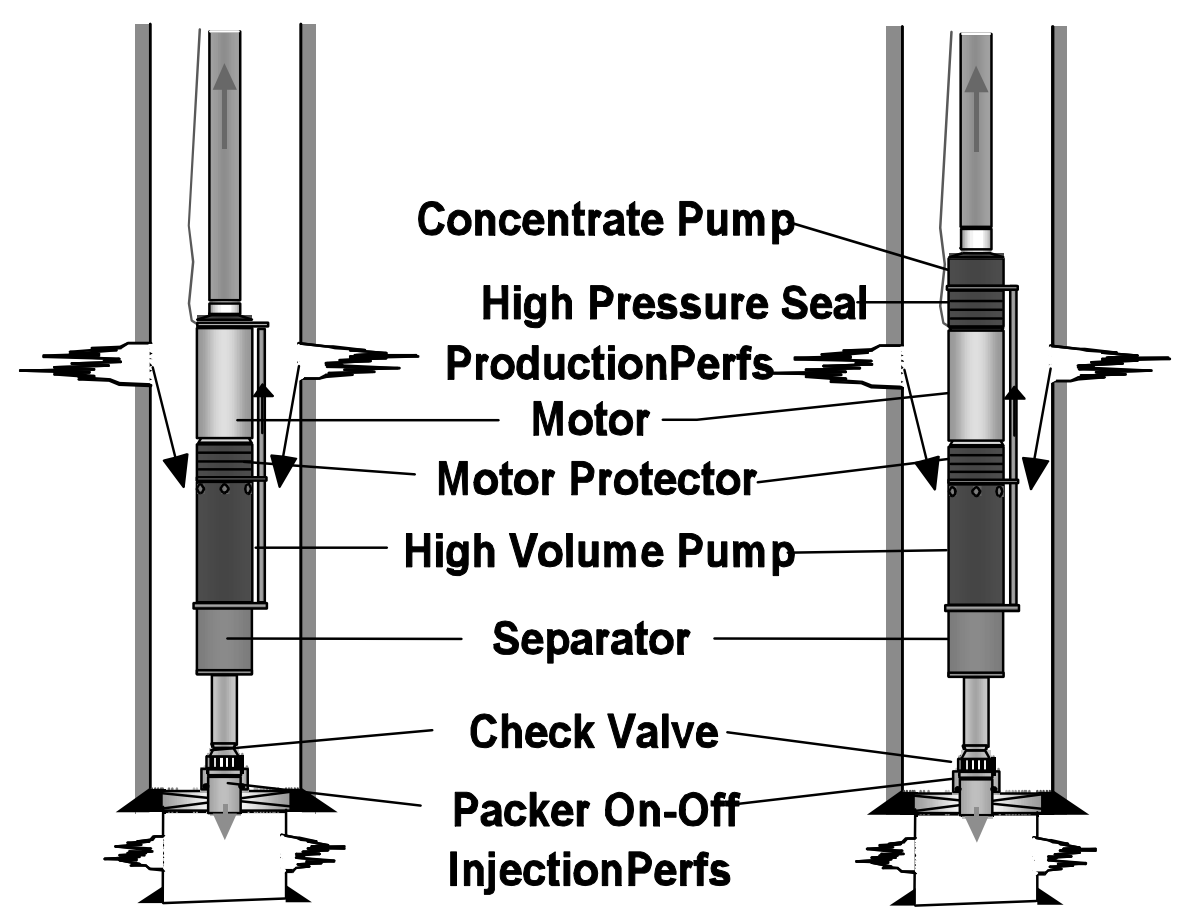

a) Single Pump Design

b) Dual Pump Design

Fig.2 - ESP Separator System Designs - provided by C-FER Technologies, Inc. 


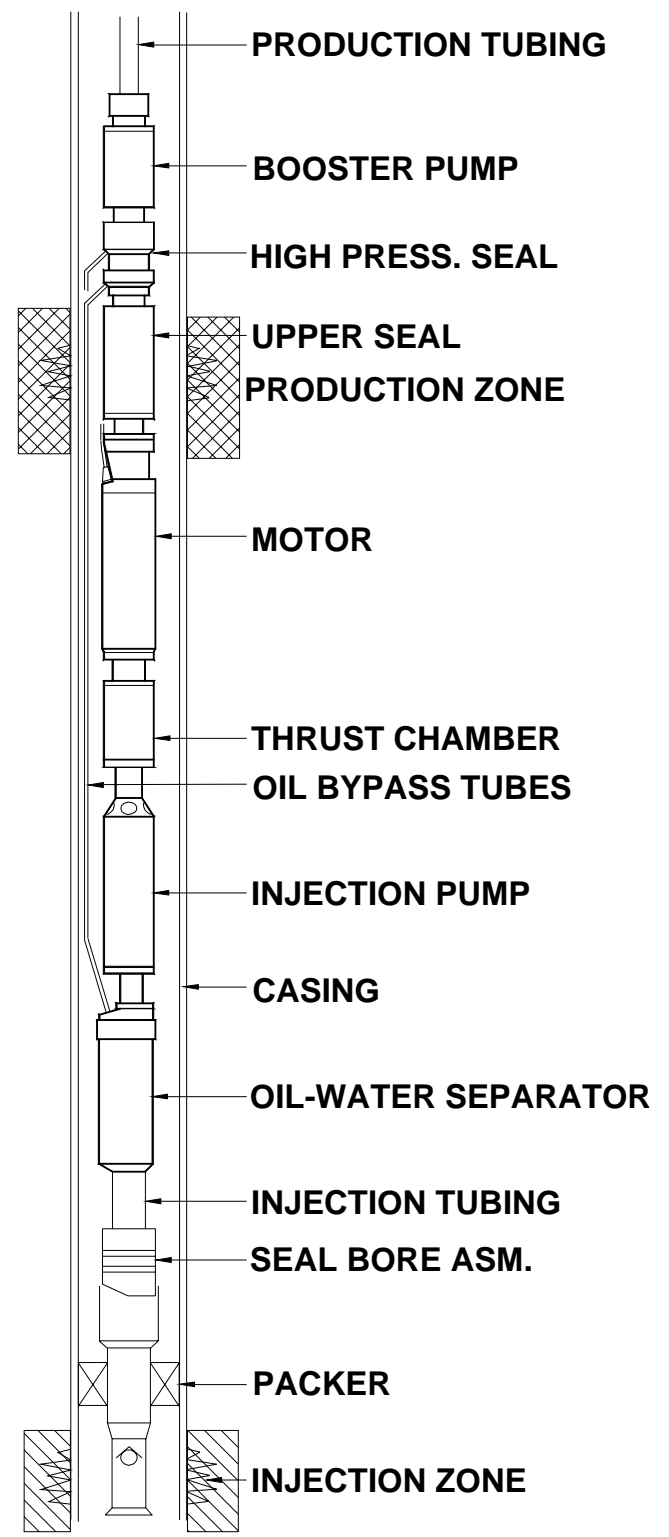

Fig. 3 - Schematic drawing of HydroSep provided by Centrilift

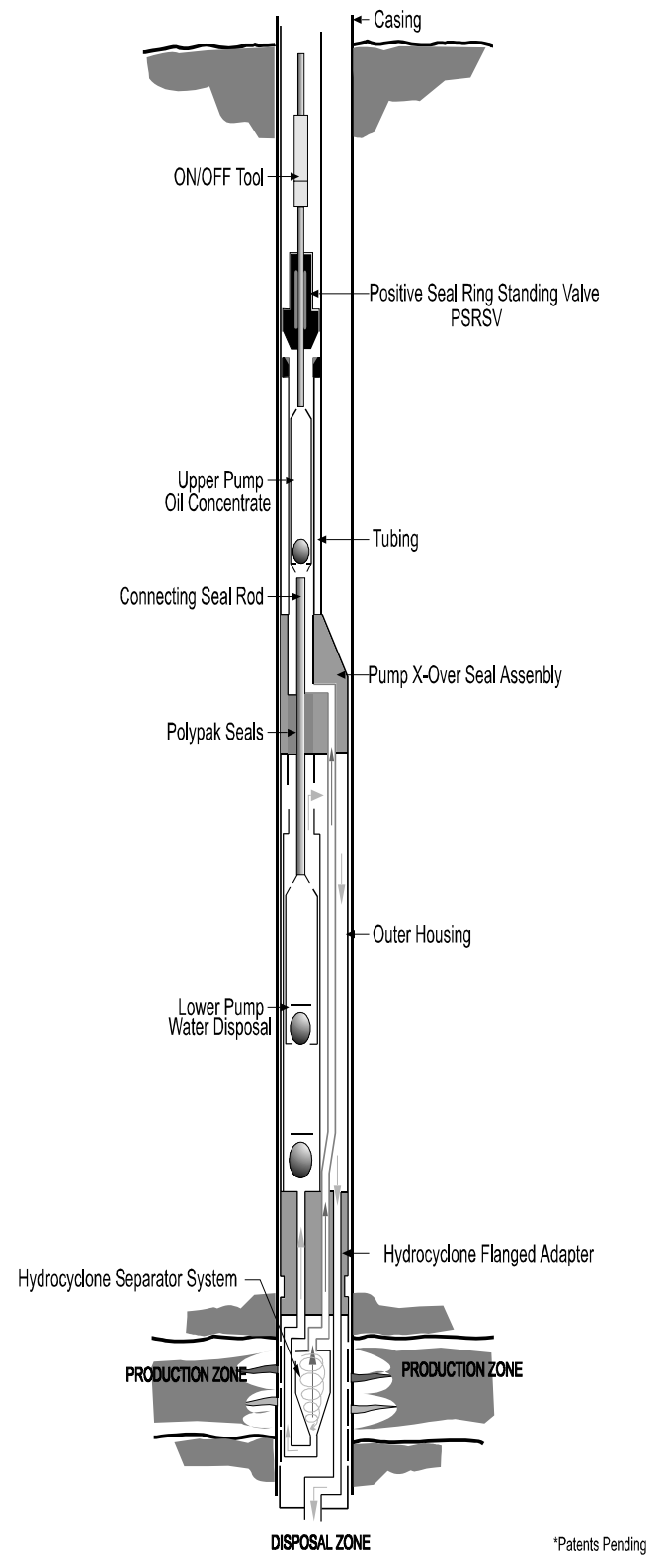

Fig. 4 - Schematic drawing of Q-Sep ${ }^{\mathrm{TM}} \mathrm{H}$ provided by Quinn's Oilfield Supply Ltd. 


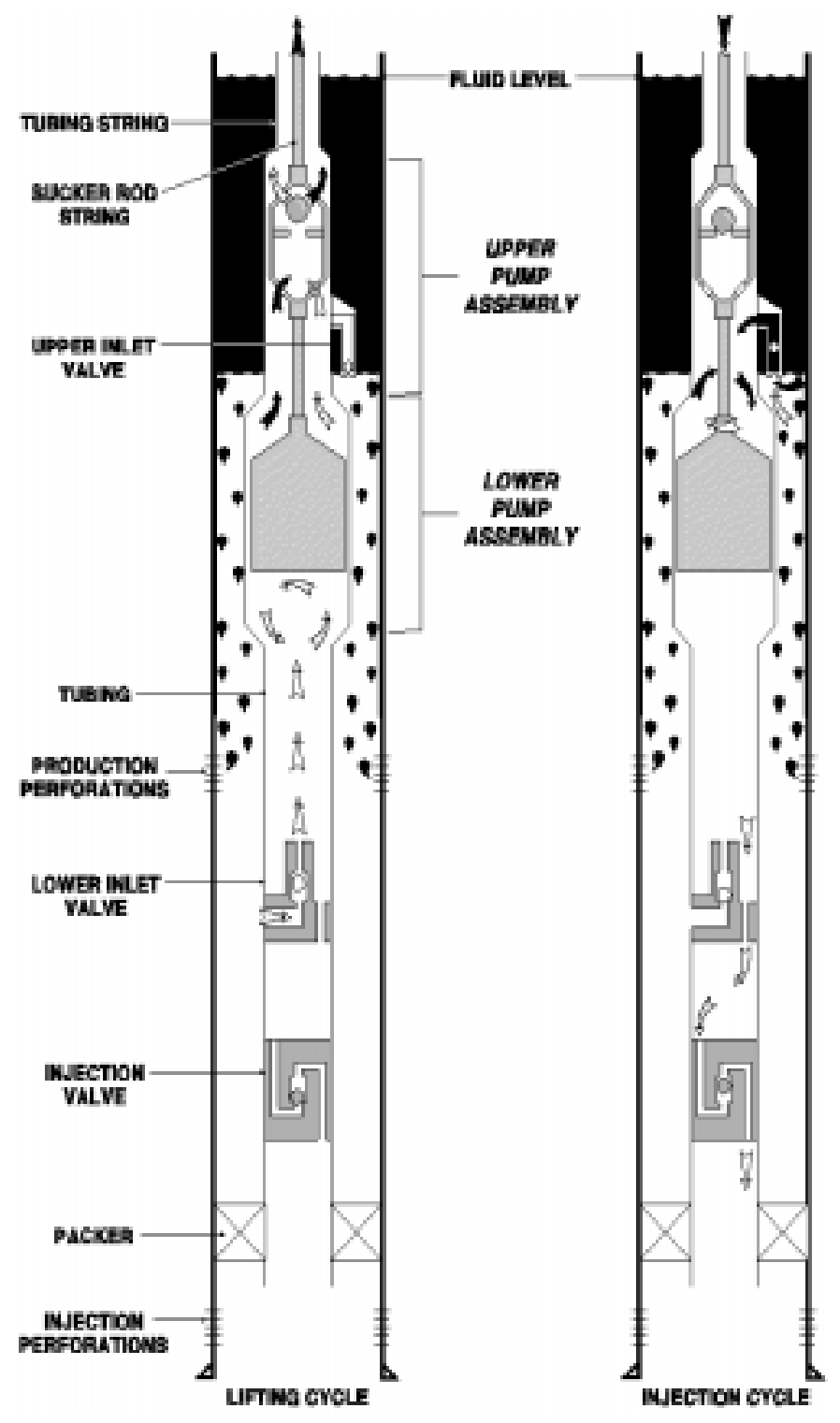

Fig. 5 - Schematic drawing of a DAPS showing the lifting and injection cycles. Reprinted from Stuebinger et al. (1997). This copyrighted figure is reproduced with the permission of the Society of Petroleum Engineers

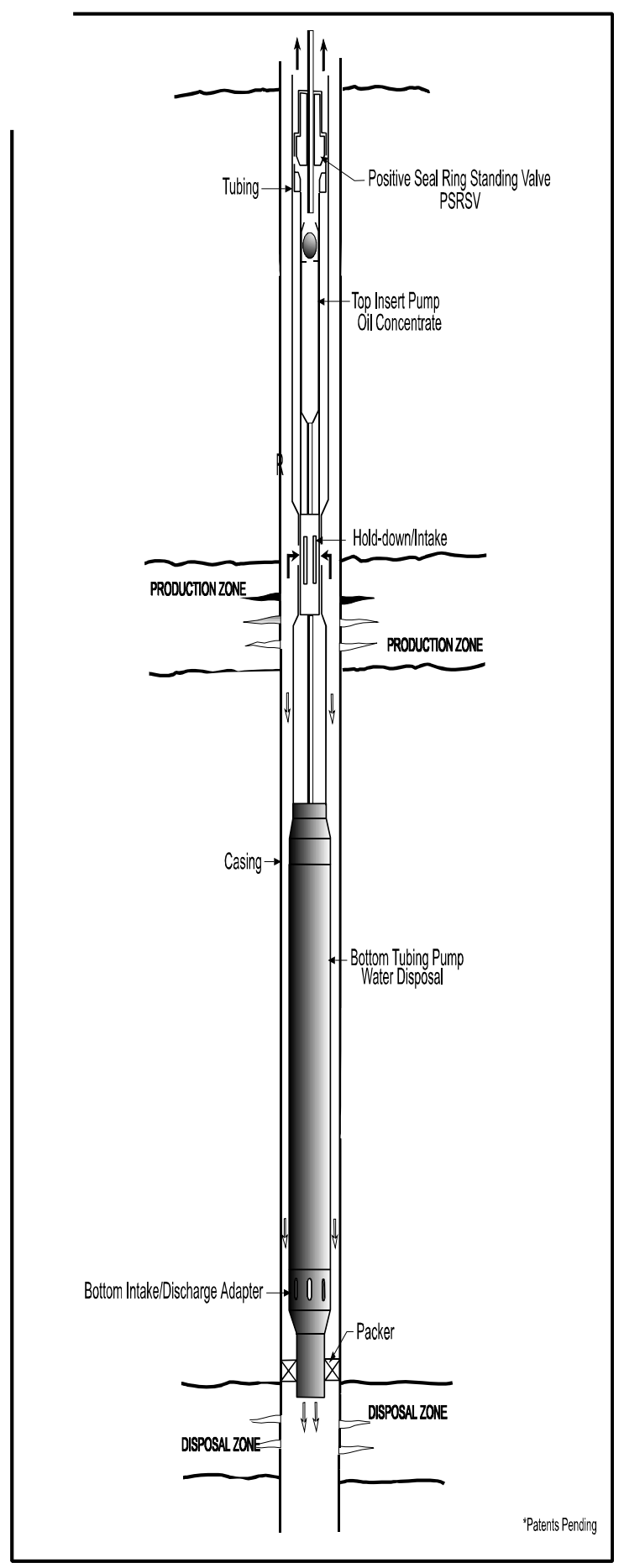

Fig. 6 - Schematic drawing of Q-Sep ${ }^{\mathrm{TM}} \mathrm{G}$ provided by Quinn's Oilfield Supply Ltd. 
Figure 7 - Schematic Drawing of Two DOWS Configurations

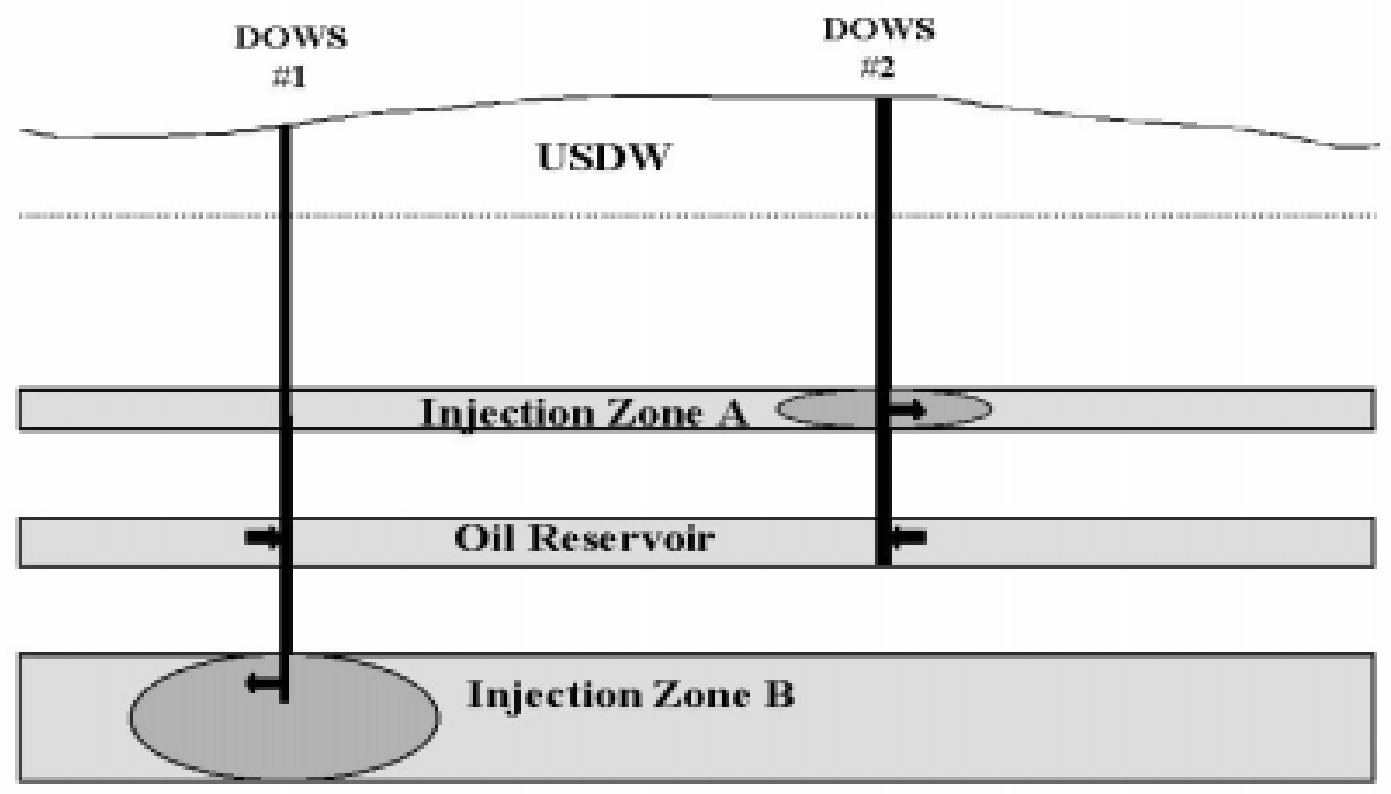

